\title{
EFFECTS OF ANTIOXIDANTS ON CONTRACTING SPINOTRAPEZIUS MUSCLE MICROVASCULAR OXYGENATION AND BLOOD FLOW IN AGED RATS
}

by

\author{
KYLE F. HERSPRING
}

B.S., Kansas State University, 2006

\begin{abstract}
A THESIS
submitted in partial fulfillment of the requirements for the degree
\end{abstract}

MASTER OF SCIENCE

Department of Kinesiology

College of Arts and Sciences

KANSAS STATE UNIVERSITY
Manhattan, Kansas

2008

Approved by:

Major Professor

Timothy I. Musch, Ph.D. 


\begin{abstract}
Aged rats exhibit a decreased muscle microvascular $\mathrm{O}_{2}$ partial pressure $\left(\mathrm{PO}_{2 m v}\right)$ at rest as well as during contractions compared to young rats and this may contribute to their reduced exercise tolerance. Age-related reductions in nitric oxide (NO) bioavailability due, in part, to elevated reactive $\mathrm{O}_{2}$ species (ROS) constrain muscle blood flow $\left(\dot{Q}_{m}\right)$. Therefore, antioxidants may restore NO bioavailability, $\dot{Q}_{m}$ and ameliorate the reduction in $\mathrm{PO}_{2 m v}$ and hence the decrease in exercise tolerance seen in aged rats. PURPOSE: To test the hypothesis that antioxidants would elevate $\dot{Q}_{m}$ at rest and during contractions and therefore $\mathrm{PO}_{2 m v}$ in aged muscle. METHODS: $\mathrm{PO}_{2 m v}$ and $\dot{Q}_{m}$ were measured in the spinotrapezius while muscle oxygen consumption $\left(\dot{\mathrm{V}}_{2 m}\right)$ was estimated in 20 anesthetized male Fisher 344 x Brown Norway hybrid (F344xBN) rats at rest and during $1 \mathrm{~Hz}$ contractions before and after antioxidant intravenous infusion $(76 \mathrm{mg} / \mathrm{kg}$ vitamin $\mathrm{C}$ and $52 \mathrm{mg} / \mathrm{kg}$ tempol). Moreover, muscle force production was measured in a subset of animals. RESULTS: Before infusion, contractions invoked a biphasic $\mathrm{PO}_{2 m v}$ that fell from $30.6 \pm 0.9 \mathrm{mmHg}$ to a nadir of $16.8 \pm 1.2 \mathrm{mmHg}$ with an 'undershoot' of $2.8 \pm 0.7$ mmHg below the subsequent steady-state $(19.7 \pm 1.2 \mathrm{mmHg})$. Antioxidants elevated baseline $\mathrm{PO}_{2 m v}$ to $35.7 \pm 0.8 \mathrm{mmHg}(\mathrm{P}<0.05)$ and reduced or abolished the 'undershoot' $(\mathrm{P}<0.05)$ without changing the steady-state contracting $\mathrm{PO}_{2 m v}$. Antioxidants did not change $\dot{Q}_{m}$ at rest but during contractions $\dot{Q}_{m}$ was reduced from $157 \pm 28$ to $91 \pm 15 \mathrm{ml}$ $\min ^{-1} 100 \mathrm{~g}^{-1}(\mathrm{P}<0.05)$. Antioxidants produced no significant effect on $\dot{\mathrm{V}} \mathrm{O}_{2 m}$. However, antioxidant supplementation produced a $16.5 \%$ decrease $(\mathrm{P}<0.05)$ in muscle force
\end{abstract}


production that occurred within the first contraction and remained throughout the duration of stimulation. In addition, the ratio of muscle force production to $\dot{\mathrm{V}} \mathrm{O}_{2 m}$ $\left(\mathrm{F} / \mathrm{V}_{2 m}\right)$ actually increased from $0.92 \pm 0.03$ to $1.06 \pm 0.6(\mathrm{P}<0.05)$ following infusion of antioxidants. CONCLUSION: Antioxidant supplementation significantly alters the balance between muscle $\mathrm{O}_{2}$ delivery and $\dot{\mathrm{VO}}_{2}$ at rest and during contractions, which modifies the microvascular $\mathrm{PO}_{2 m v}$ profile. Specifically, antioxidants elevate $\mathrm{PO}_{2 m v}$, which improves the potential for diffusive blood-myocyte flux. This effect arises, in part, from the unanticipated fall in muscle force production consequent to antioxidant supplementation. 


\section{Table of Contents}

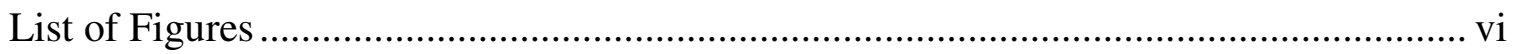

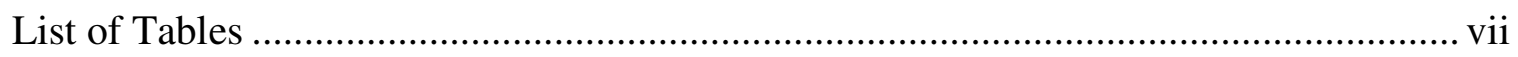

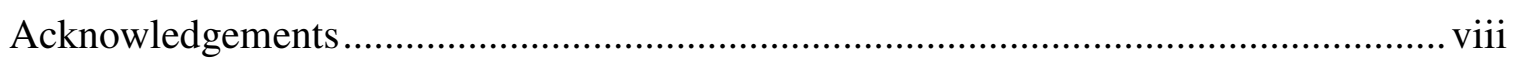

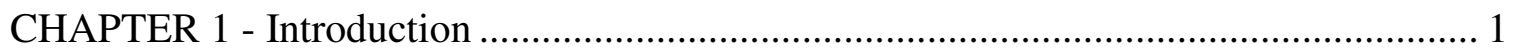

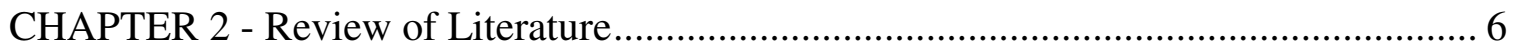

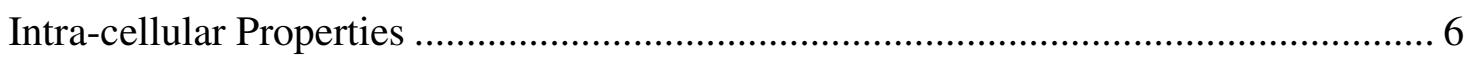

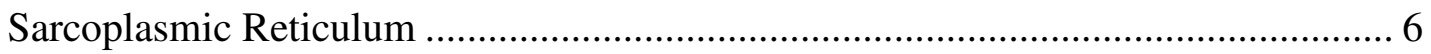

Sodium-potassium Pumps............................................................................... 7

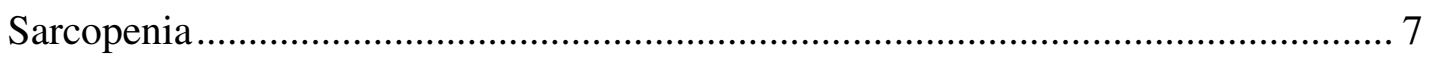

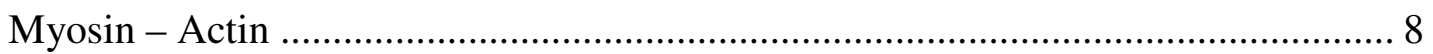

Extra-cellular Properties .................................................................................... 8

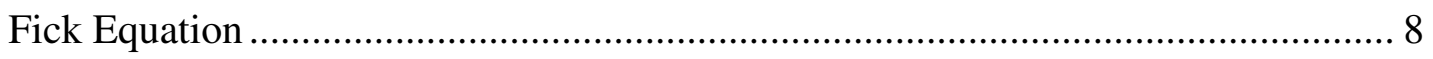

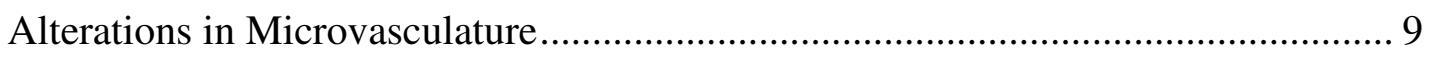

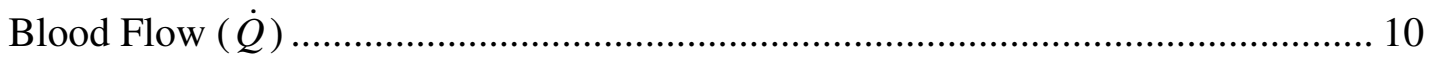

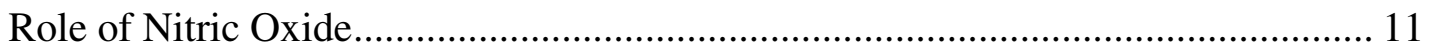

Free Radicals and NO Bioavailability ................................................................ 12

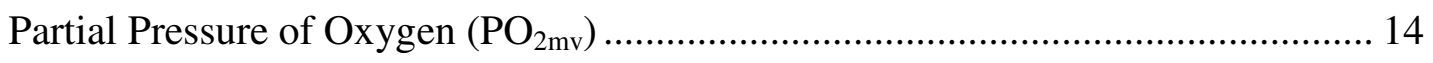

Antioxidant Supplementation .......................................................................... 15

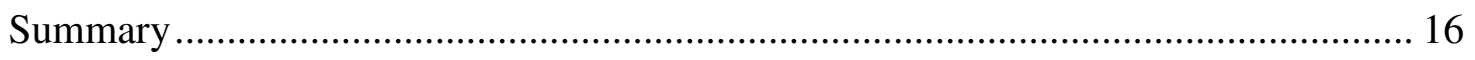

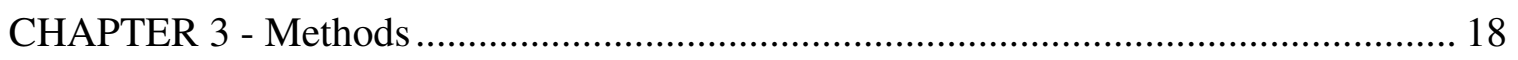

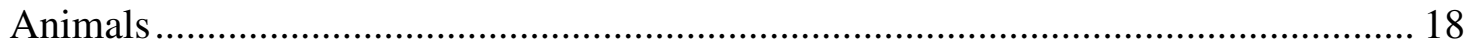

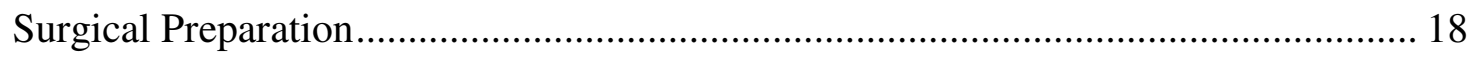

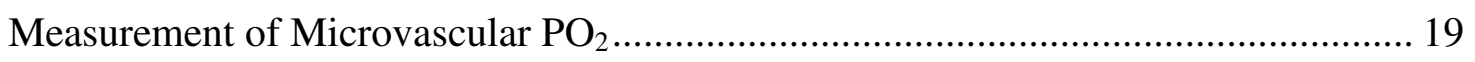

Measurement of Spinotrapezius Blood Flow............................................................. 19

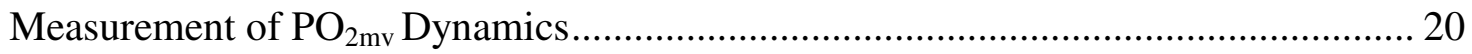

Measurement of Spinotrapezius Force Production ...................................................... 21

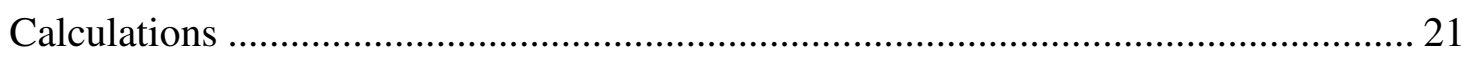

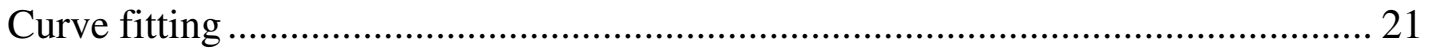




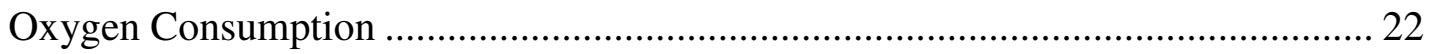

Stability and Reproducibility of the Spinotrapezius Preparation............................... 22

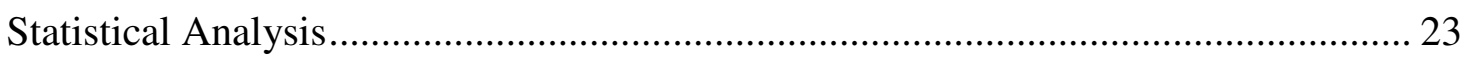

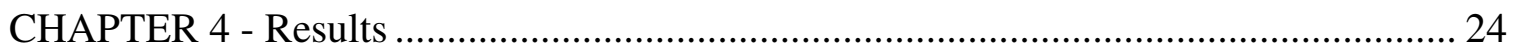

Microvascular Partial Pressure of Oxygen $\left(\mathrm{PO}_{2 m v}\right)$................................................. 24

Muscle Blood Flow $\left(\dot{Q}_{m}\right)$ and Conductance ........................................................ 25

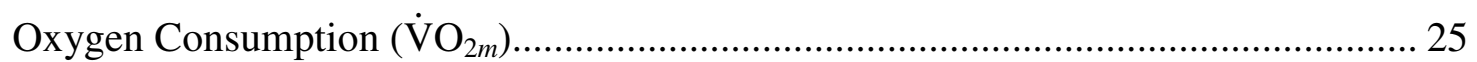

Muscle Force Production: ...................................................................................... 26

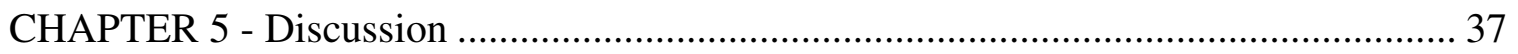

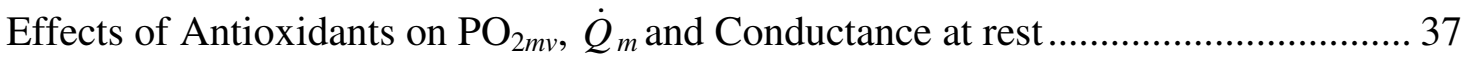

Effects of Antioxidants on the transition of $\mathrm{PO}_{2 m v}$ from rest to exercise: .................. 39

Other Potential Mediators of the $\mathrm{PO}_{2 m v}$ Profile ...................................................... 41

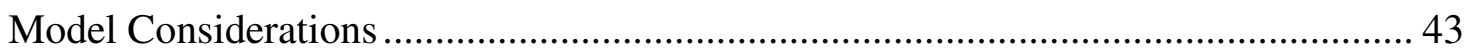

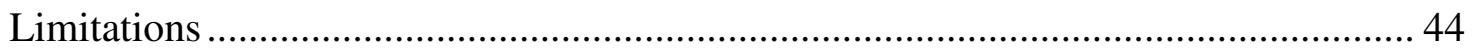

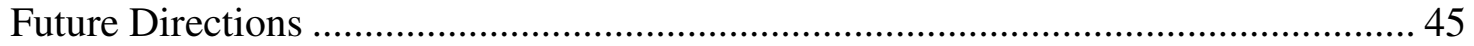

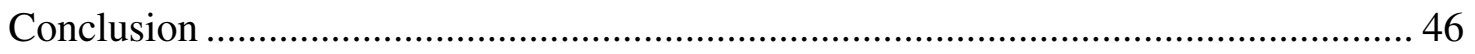

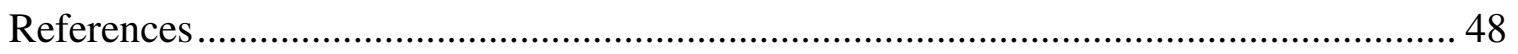




\section{List of Figures}

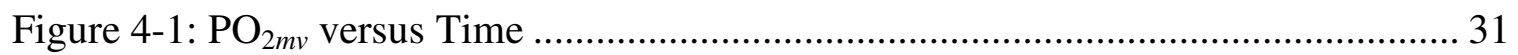

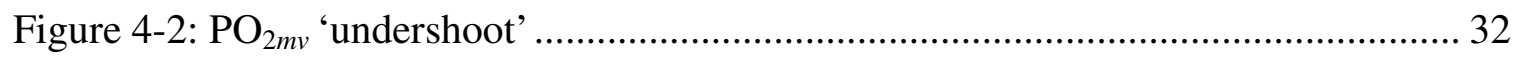

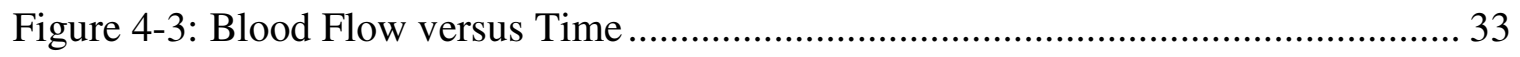

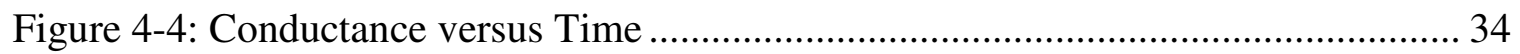

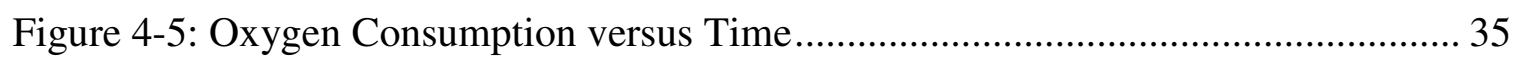

Figure 4-6: Muscle Force Production versus Time .................................................... 36

Figure 5-1: Biphasic Muscle Force Production Curve ............................................. 47 


\section{List of Tables}

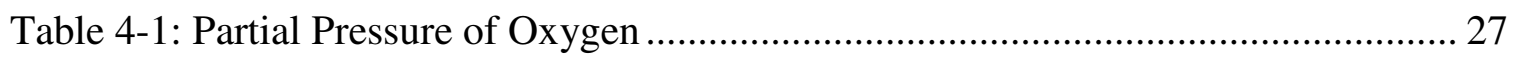

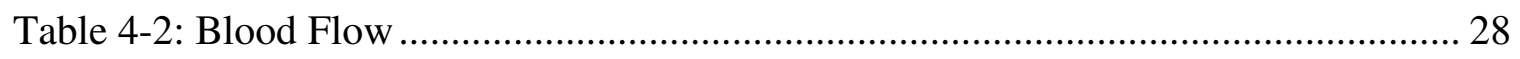

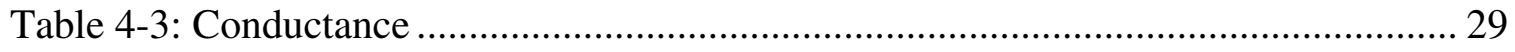

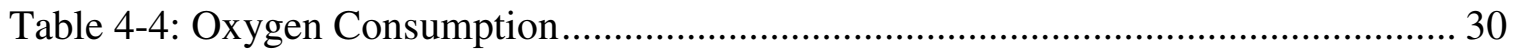




\section{Acknowledgements}

I would foremost like to thank Drs Timothy Musch and David Poole for their scientific mentoring during this investigation. In addition, I would like to thank Dr. Leonardo Ferreira for his guidance and tremendous help during the experiment protocol and vast amount of time spent explaining material to me. I would also like to thank Dr. Craig Harms for his brilliant insights into this investigation. I would also like to thank Sue Hageman, Scott Hahn and Steven Copp for their technical assistance during this study, without it this investigation would not have been possible. I would like to thank my lab partners and co-workers for supplying an incredible work environment, which made work on this project and everyday in this lab enjoyable. Finally, I would like to thank my fiancé and family for their support throughout this journey. This work was supported by AHA Heartland Affiliate Grant \#070090Z. 


\section{CHAPTER 1 - Introduction}

Most individuals experience significant age-related reductions in exercise tolerance after attaining adulthood. These reductions in exercise capacity are associated with decrements in both maximal oxygen $\left(\mathrm{O}_{2}\right)$ uptake $\left(\dot{\mathrm{V}}_{2 \max }\right)$ and physical endurance capacity at submaximal work rates $(3,40,45,64)$. Although aged individuals possess a significantly lower $\dot{\mathrm{V}} \mathrm{O}_{2 \max }$ when compared to their younger counterparts $(3,14,21,46$, 59) some do not demonstrate a reduced maximal cardiac output ( $\dot{Q})$ even though their maximal heart rate $\left(\mathrm{HR}_{\max }\right)$ decreases with age $(14,21,45,59)$. Specifically, McGuire et al. (59) showed that maximal stroke volume $\left(\mathrm{SV}_{\max }\right)$ increased with age, compensating for the decreased $\mathrm{HR}_{\max }$ and thereby maintaining maximal cardiac output and whole body $\mathrm{O}_{2}$ delivery. This suggests that age-related declines in exercise tolerance, in so far as they relate to the $\mathrm{O}_{2}$ transport capacity, may be ascribed to peripheral alterations that act to decrease the fractional extraction of $\mathrm{O}_{2}$ from the blood (i.e. arterial-mixed venous difference; $\left.\mathrm{a}-\mathrm{vO}_{2}\right)(59)$. This reduced a- $\mathrm{vO}_{2}$ difference may be accompanied by reductions in mitochondrial volume density and function in addition to a decreased lineal density of flowing capillaries (74).

At rest, when compared to their young counterparts, aged rats exhibit a: 1) higher muscle capillary red blood cell $(\mathrm{RBC})$ velocity $\left(\mathrm{V}_{\mathrm{RBC}}\right)$ and flux $\left.\left(\mathrm{F}_{\mathrm{RBC}}\right)(74) 2\right)$ reduced partial pressure of oxygen $\left(\mathrm{PO}_{2 m v}\right)$ in the resting muscle microvasculature that is maintained throughout the rest-contractions transition (9). Thus, a decreased $\mathrm{PO}_{2 m v}$ driving pressure is present in aged rats when compared to their younger counterparts and one possible explanation for this phenomenon is age-related reductions in both tissue and/or vascular nitric oxide (NO) bioavailability are present (12, 27, 28, 79, 80, 84). 
Based on these previous findings (9), one would hypothesize that bulk blood flow $(\dot{Q})$ during exercise decreases with age. Contrary to this hypothesis, it has been shown that bulk $\dot{Q}$ to the hindlimbs of rats during submaximal exercise is not decreased in the aged when compared to the young (61). There is, however, a redistribution of blood flow from the muscles containing a majority of highly oxidative fibers to those muscles containing a majority of highly glycolytic fibers. These findings suggest that age-related changes may be occurring at the microcirculatory level that are likely to influence the $\mathrm{O}_{2}$ delivery-to- $\mathrm{O}_{2}$ utilization relationship during muscle contraction (9).

In healthy young individuals muscle blood flow $\left(\dot{Q}_{m}\right)$ increases immediately at the onset of muscle contractions and is sustained during the steady-state $(50,51,78)$ such that the $\dot{Q}_{m}$ is directly related to the rate of oxidative metabolism in muscle $\left(\dot{\mathrm{V}}_{2 m}\right)$ $(30,70)$. In aged individuals $\dot{Q}_{m}$ is sometimes found to be lower than that in young subjects during exercise $(36,53,66,67)$. However, in these and other studies in humans technical considerations precluded assessment of whether there was an age-related redistribution of $\dot{Q}_{m}$ within or between individual muscles during exercise.

The overall reduction in $\dot{Q}_{m}$ found in aged individuals is thought to be related directly to compromised arteriolar vasomotor control $(25,60,67)$. Since the production and release of NO from vascular endothelial cells is considered to be a major contributor to the skeletal muscle hyperemia seen in healthy young individuals during exercise, the possibility exists that there may be an impaired NO-mediated vasodilation in aged individuals $(43,44,77)$. In support of this notion it has been shown that the relative contribution of NO to the vascular control of skeletal muscle is reduced in aged 
individuals $(12,27,28,79,80,84)$ and thus decreased NO bioavailability may potentially explain the age-related reductions in the $\dot{Q}_{m}$ response $(25,61,67)$.

The mechanism(s) responsible for this decrease in NO bioavailability in aged individuals may result, in part, from an increased mitochondrial leakage of reactive oxygen species (ROS) $(27,35,80)$. ROS can influence NO bioavailability in two ways. First, ROS scavenge NO to produce peroxynitrite which reduces NO bioavailability whilst simultaneously producing another ROS. Second, ROS decrease the concentration of the NO synthase (NOS) co-factor tetrahydrobiopterin (BH4), which is essential for the production of NO by NOS $(38,39)$. If either of these mechanisms contribute to the reduction in NO bioavailability in aged skeletal muscle, supplementation with antioxidants, sufficient to decrease the amount of circulating ROS, may help restore endothelial (i.e. arteriolar) function and NO bioavailability in aged individuals $(27,79)$.

The partial pressure of oxygen in the microvasculature supplying muscle $\left(\mathrm{PO}_{2 m v}\right)$ is dependent upon the ratio of oxygen delivery to the muscle $\left(\dot{Q} \mathrm{O}_{2 m}\right)$ and $\dot{\mathrm{V}} \mathrm{O}_{2 m}$ (i.e., $\dot{Q} \mathrm{O}_{2 m} / \dot{\mathrm{V}}_{2 m}$ ). The maintenance of this ratio and consequently $\mathrm{PO}_{2 m v}$, during exercise is crucial in order to provide an adequate pressure head to drive $\mathrm{O}_{2}$ flux across the blood-myocyte interface and deliver $\mathrm{O}_{2}$ to the mitochondria during contractions (i.e. transition and steady-state) $(7,8,31,65,85)$. Upon the initiation of muscle contractions in young healthy rats, $\dot{Q} \mathrm{O}_{2 m}$ increases rapidly and in parallel with $\dot{\mathrm{V}} \mathrm{O}_{2 m}$ such that there is $\mathrm{a} \sim 10-20$ second delay in the fall of $\mathrm{PO}_{2 m v},(30)$. As the muscle contractions continue $\mathrm{PO}_{2 m v}$ falls and eventually reaches a steady state.

In young, healthy individuals performing moderate-intensity exercise it is generally accepted that the increased rate of in $\dot{Q} \mathrm{O}_{2 m}$ does not limit $\dot{\mathrm{V}} \mathrm{O}_{2 m}(11,50)$. Thus, 
in young healthy individuals, $\dot{Q}_{m}$ and $\dot{Q} \mathrm{O}_{2 m}$ increase at the same rate or occasionally faster than $\dot{\mathrm{VO}}_{2 m}$ at least for the first 10-20 s, which prevents $\mathrm{PO}_{2 m v}$ from falling $\left(\dot{Q} \mathrm{O}_{2 m} / \dot{\mathrm{VO}}{ }_{2 m}\right)$ (9-11). Beyond the first $10-20 \mathrm{~s}$, the $\dot{Q} \mathrm{O}_{2 m} / \dot{\mathrm{V}} \mathrm{O}_{2 m}$ ratio falls and $\mathrm{PO}_{2 m v}$ demonstrates an exponential decrease to the steady-state, reflecting the increased fractional $\mathrm{O}_{2}$ extraction. The net effect of this behavior is that $\mathrm{PO}_{2 m v}$ in young animals is maintained at high levels across the rest-contraction transition thereby improving mitochondrial $\mathrm{O}_{2}$ delivery, which permits more reliance on oxidative metabolism. However, aging is associated with an altered (i.e., lowered) $\mathrm{PO}_{2 m v}$ profile (9) that potentially reflects peripheral vascular derangements. In aged muscle there is a reduced $\mathrm{PO}_{2 m v}$ following the onset of contractions, which results in a lower $\mathrm{O}_{2}$ driving pressure across the blood-muscle interface $(9,15)$. This reduction in $\mathrm{O}_{2}$ driving pressure is expected to slow $\dot{\mathrm{VO}}_{2}$ kinetics, increase the $\mathrm{O}_{2}$ deficit (26) and increase mitochondrial ROS production (16). If interventions aimed at restoring vascular endothelial function do, in fact, augment $\dot{Q} \mathrm{O}_{2 m}$ this should improve $\mathrm{PO}_{2 m v}$ kinetics (i.e. raise the absolute $\mathrm{PO}_{2 m v}$ across the transtion) following the onset of muscle contractions. The improved $\mathrm{PO}_{2 m v}$ kinetics would potentially increase blood-myocyte $\mathrm{O}_{2}$ flux in aged individuals and thereby potentially enhance exercise tolerance.

Ferreira and colleagues have shown previously that increasing NO bioavailability improved the $\mathrm{PO}_{2 m v}$ kinetics profile in both young healthy rats and those with experimentally-induced heart failure $(29,30)$. The opposite effect occurred with NOS inhibition (30). One potential method for augmenting NO-mediated vasodilation in skeletal muscle is via antioxidant supplementation. Antioxidant supplementation allows an increase in NO bioavailability by binding to ROS thereby inactivating them $(27,79)$. 
In the present investigation we examined the role of antioxidant supplementation on $\dot{Q} \mathrm{O}_{2}$ and $\mathrm{PO}_{2 m v}$ across the rest-to-contractions transition in the spinotrapezius muscle of aged rats. Specifically, we tested the hypotheses that after antioxidant supplementation: 1) the reduced $\mathrm{PO}_{2 m v}$ normally found in the resting muscle of aged rats would be alleviated; 2) the elevated resting $\mathrm{PO}_{2 m v}$ of aged rats would be associated with an increase in resting $\dot{Q}_{m}$ to muscle; 3 ) there would be an increase in $\dot{Q}_{m}$ to the contracting muscle which would elevate the $\dot{Q} \mathrm{O}_{2 m} / \dot{\mathrm{V}} \mathrm{O}_{2 m}$ ratio and thus $\mathrm{PO}_{2 m v}$ in the exercising steady-state; 4) the dynamic $\mathrm{PO}_{2 m v}$ undershoot and prolonged $\mathrm{PO}_{2 m v}$ kinetics that are commonly found in the transition from rest to exercise in aged rats (9) would be reduced or eliminated. 


\section{CHAPTER 2 - Review of Literature}

The reduction in exercise capacity with aging is associated with reductions in both maximal aerobic capacity and submaximal endurance capacity $(3,40,45,64)$. However, since the reductions in $\dot{\mathrm{VO}}_{2 \max }$ and endurance capacity found with aging may occur through different physiological mechanisms, their relative importance and contributions to the overall reduction in exercise capacity found in aging individuals remain obscure. Therefore, it is important to look at both the intra-cellular and the extra-cellular aspects that effect endurance capacity.

\section{Intra-cellular Properties}

\section{Sarcoplasmic Reticulum}

The sarcoplasmic reticulum (SR) functions to uptake and release calcium $\left(\mathrm{Ca}^{2+}\right)$ to help either initiate or sequester skeletal muscle contractions. The SR does not appear to have any structural deformations that occur with aging (55). There is no evidence that the number of SRs are changed with age $(32,63)$. However, there is a lower rate of $\mathrm{Ca}^{2+}$ uptake that occurs in the SR of slow twitch muscle fibers (63). The enzyme responsible for $\mathrm{Ca}^{2+}$ uptake is $\mathrm{Ca}^{2+}$-ATPase. This enzyme is found in lower concentrations (47) and appears to be less stable in the skeletal muscle of aged individuals when compared to their younger counterparts (55). 


\section{Sodium-potassium Pumps}

The aging process causes a decrease in the number of sodium-potassium $\left(\mathrm{Na}^{+} / \mathrm{K}^{+}\right)$ pumps along with the concentration of $\mathrm{Na}^{+} / \mathrm{K}^{+}$ATPase (64). The major role of these $\mathrm{Na}^{+} / \mathrm{K}^{+}$pumps is to maintain the cells membrane potential. $\mathrm{Na}^{+} / \mathrm{K}^{+}$ATPase is an enzyme that plays a similar role when compared to $\mathrm{Ca}^{2+}$-ATPase. Their role in skeletal muscle fibers is to allow for an action potential to be transported from one region to another region allowing for a muscle contraction. There is also a decrease in the ability of motor axons and nerve muscular junctions to function properly that occurs with aged humans and animals $(5,71)$. Any alterations within the muscle fiber to produce action potentials could produce a decrease in skeletal muscle contractile function. The end result being a decreased muscle force production and decrements in exercise tolerance.

\section{Sarcopenia}

Another age related phenomenon that contributes to reduce muscle function is the atrophy of muscle mass, which is known as sarcopenia $(18,72)$. The defects in aged skeletal muscle mentioned above may play a role in sarcopenia as well as the trend of physical inactivity in aged individuals. Skeletal muscles contain cells called satellite cells and it is these cells job to inhibit sarcopenia by regenerating skeletal muscle fibers (57). In rat skeletal muscle it has been shown that the number of satellite cells is significantly reduced with age $(1,33)$. Moreover, this reduction leads to an increased rate of atrophy $(20,33)$. 


\section{Myosin - Actin}

Although many of the mechanisms associated with muscle contraction become dysfunctional with advancing age, other components associated with excitationcontraction coupling are maintained. For example, myosin and actin filaments which comprise the muscle contractile elements are not affected with age (81). In the presence of $\mathrm{Ca}^{2+}$, myosin and actin interact with each other forming cross bridges which produces a muscle contraction. Since myosin, actin and the sarcoplasmic reticulum are not affected by age there must be other villains that cause the reductions in both muscle performance and exercise tolerance in aged individuals. These villains are the reduced ability of $\mathrm{Ca}^{2+}$ ATPase and $\mathrm{Na}^{+} / \mathrm{K}^{+}$-ATPase to work properly along with lowered number of properly working $\mathrm{Na}^{+} / \mathrm{K}^{+}$pumps.

\section{Extra-cellular Properties}

In conjunction with decrements in skeletal muscle function, aged individuals possess a significantly lower $\dot{\mathrm{V}}_{2 \max }$ when compared to their young counterparts $(3,21$, $46,59)$. As with muscle performance, it is important to concentrate on the factors that affect $\dot{\mathrm{V}} \mathrm{O}_{2 \max }$.

\section{Fick Equation}

The Fick equation is the gold standard when evaluating $\dot{\mathrm{V}}_{2 \max }$. The Fick equation states $\dot{\mathrm{V}} \mathrm{O}_{2}=\dot{Q} \times$ a-vO $\mathrm{v}_{2}$, where $\dot{Q}$ is cardiac output and/or the blood flow and a-vO $\mathrm{v}_{2}$ is the arterial - mixed venous $\mathrm{O}_{2}$ difference. Moreover, $\dot{Q}=\mathrm{HR} \times \mathrm{SV}$, where $\mathrm{HR}$ is heart rate and $\mathrm{SV}$ is stroke volume. Maximal heart rate has been shown to decrease 
with age $(21,45,59,75)$. McGuire et al. demonstrated through a 30 year old longitudinal study that $\mathrm{SV}_{\max }$ increases with age, compensating for the decreased $\mathrm{HR}_{\max }$, thereby maintaining cardiac output (59). The presence of a maintained cardiac output indicates that central adaptations are not the cause for the reduced $\dot{\mathrm{VO}}_{2 \max }$ seen in aged individuals. The answer for this decrease $\mathrm{VO}_{2 \max }$ may lie in the impaired effectiveness of the peripheral $\dot{Q}(59)$.

When examining the second half of the Fick equation it becomes evident that aged individuals suffer from a reduced a- $\mathrm{vO}_{2}$ difference that is accompanied by reductions in mitochondrial oxidative enzymes and lineal density found within the skeletal muscles. Hepple et al. (40) showed a decreased $\dot{\mathrm{V}}_{2 \max }$ in aged individuals compared to that of young individuals receiving the same amount of bulk $\dot{Q}$ to the skeletal muscle. This is indicative of a reduced capacity to extract $\mathrm{O}_{2}$. Therefore, it is believed that alterations in the microcirculation produce a decrease extraction ability and cause decrements in $\dot{\mathrm{VO}}_{2 \max }$.

\section{Alterations in Microvasculature}

Reductions in a- $\mathrm{vO}_{2}$ found with aging might be related to alterations in the microcirculation and these alterations are primarily due to peripheral derangements (61). One of the greatest indications of an impaired microcirculatory system would be an impaired diffusing capacity of $\mathrm{O}_{2}\left(\mathrm{DO}_{2}\right)$ across the blood-myocyte barrier. Hence, if a low $\mathrm{DO}_{2}$ were present then extraction of $\mathrm{O}_{2}$ by skeletal muscle would be reduced and a lower exercise performance would transpire. This is evident when one analyzes the diffusion capacity equation solved for oxygen extraction $\left[\mathrm{O}_{2}\right.$ extraction $=1-\mathrm{e}^{\left(-\mathrm{DO}_{2} / \mathrm{BV}_{\mathrm{RBC}}\right)}$, where $B$ is the slope of the $\mathrm{O}_{2}$ dissociation curve]. In regard to diffusion capacity, aged 
individuals have a higher capillary $\mathrm{V}_{\mathrm{RBC}}$ and $\mathrm{F}_{\mathrm{RBC}}$ then young individuals, which causes a decreased transit time for diffusion to occur in the muscle (74). The decrease in transit time allows for less time to offload $\mathrm{O}_{2}$ from the $\mathrm{RBC}$ putting a greater strain on the muscle. It has been hypothesized that reductions in both $\mathrm{V}_{\mathrm{RBC}}$ and $\mathrm{F}_{\mathrm{RBC}}$ occur during muscle contractions in aged individuals. However, experimental evidence supporting this notion has yet to be produced and needs to be the focus of future studies.

Capillarization also appears to be disrupted in aging. The linear density of flowing capillaries is reduced with age (74) and this contributes to an increased $V_{R B C}$ and $F_{R B C}$ as stated above and potentially contributes to the decrease in a- $\mathrm{vO}_{2}$ difference in aged individuals when compared to young individuals. However, aged individuals demonstrate a maintained or improved capillary-fiber-interface, thus indicating microvascular functional derangements $(41,56)$.

\section{Blood Flow $(\dot{Q})$}

At the onset of contractions an increased $\dot{Q}_{m}$ is needed to meet the increased $\mathrm{O}_{2}$ demand by the contracting muscle. The increase in $\dot{Q}_{m}$ is distinguished by three phases. The first of these phases is possibly due to the combination of a muscle pump effect and some degree of rapid vasodilation (82). Phase 1 normally lasts around 10-20 seconds. Phase 2 is illustrated by a continued increase in $\dot{Q}_{\mathrm{m}}$ due to the increased vascular relaxation within the working muscle along with an increased vasoconstriction within the non-working muscles. Phase 3 occurs when the $\dot{Q}_{\mathrm{m}}$ is able to meet the demand of the working muscle for a continuous period of time producing a steady state.

In healthy young individuals, $\dot{Q}_{\mathrm{m}}$ increases with the onset of contractions and is 
sustained during the steady state $(50,51,78)$. This increase in $\dot{Q}_{m}$ is directly related to the oxidative metabolism found in muscle $\left(\mathrm{V}_{2 m}\right)(30,70)$ and is directly related to exercise tolerance and capacity. In aged subjects $\dot{Q}_{m}$ has shown to be reduced significantly compared to young subjects causing a greater reliance on non-oxidative metabolism $(36,53,66,67)$. This decreased $\dot{Q}_{m}$ is directly related to modification in the processes that cause the arteriolar vessels to dilate $(60,67)$.

Although a majority of studies have shown that $\dot{Q}_{\mathrm{m}}$ is decreased in aged individuals, Musch et al. (61) showed that bulk $\dot{Q}_{\mathrm{m}}$ was maintained in aged in rats during submaximal exercise. Surprisingly, Musch et al. (61) also demonstrated a redistribution of $\dot{Q}_{\mathrm{m}}$ from the muscles containing a majority of highly oxidative fibers to the muscles containing a majority of highly glycolytic fibers. The reduced $\dot{Q}_{\mathrm{m}}$ to the SO fibers could potentially cause an earlier onset of fatigue via promoting the utilization of non-oxidative metabolism. Moreover, these results indicate that age-related changes may be occurring in the microcirculation.

\section{Role of Nitric Oxide}

The vascular tone in skeletal muscle is continuously changing between vasoconstriction and vasodilation depending on the demands. The modification of the vascular wall is of great importance to either increase or decrease $\dot{Q}_{m}$. Thus, any alterations that cause impairment on the vascular tone could be detrimental. This control is of vital importance in terms of directing blood towards the working muscle where vasodilation must occur and reflecting blood away from the non-working muscle by means of vasoconstriction. Many plausible compounds (NO, EDHF, prostaglandins, 
hydrogen peroxide, inorganic phosphate, etc) have been proposed for causing vasodilation allowing for an increased $\dot{Q}_{m}$.

Aged individuals demonstrate an impaired endothelial-mediated vasodilation in the working skeletal muscle. The major player in the reduced endothelial vasodilation is believed to be the reduced bioavailability of NO, which is believed to be a major contributor to the skeletal muscle hyperemia seen in healthy young individuals during exercise $(43,44,77)$. NO is synthesized by NO synthase (NOS) which is present in three different types of isoforms; type I NOS (neural), type II NOS (inducible) and type III NOS (endothelial) (68). All three isoforms of NOS, in combination with L-arginine, produce NO. Certain compounds seem to indicate that NO plays a vital role in increasing $\dot{Q}_{\mathrm{m}}$ to the exercising muscle. NG-nitro-L-arginine methyl easter (L-NAME) has shown to inhibit the bioavailability of NO (30). Administration of sodium nitro-prusside (SNP) has shown to increase the bioavailability of NO (30). Previous studies have shown that both L-NAME and SNP produce decreases and increases $\dot{Q}_{m}$ respectively. Therefore, it is believed that NO plays a vital role in the regulation of $\dot{Q}_{m}$ and the hyperaemic response to exercise. Thus, any dysfunction in the production of NO and/or regulation of vascular tone could impair the hyperaemic response to exercise with the eventually outcome being a worsening in an individual's endurance capacity.

\section{Free Radicals and NO Bioavailability}

It has been shown that there is reduction in vascular NO available in aged individuals $(12,27,28,79,80,84)$, which may help explain the reduced $\dot{Q}_{m}$ response to muscle contractions $(61,67)$. This decrease in NO bioavailability may be explained by 
the increasing leakage of reactive oxygen species (ROS) from the mitochondria in aged individuals $(27,35,80)$. ROS are a naturally occurring byproduct of oxidative metabolism that leak from the mitochondria. In young healthy individuals, leaked ROS account for about 2-3\% of mitochondrial oxygen consumption (69). In aged individuals, generation and leakage of ROS are accelerated compared to their young counterparts. The most common leaked ROS is superoxide $\left(\mathrm{O}_{2}^{-}\right)$anion, which can undergo electron exchange producing hydrogen peroxide $\left(\mathrm{H}_{2} \mathrm{O}_{2}\right)$ and a hydroxyl radical. All can cause detrimental effects to the cell.

ROS do not always have a negative effect. $\mathrm{H}_{2} \mathrm{O}_{2}$ can play a vital role in producing vasodilation in skeletal muscle (19). The increased production of ROS is not the only side effect of aging. Aged individuals also appear to have a decreased antioxidant defense system against these free radicals. This imbalance between the increased $\mathrm{O}_{2}{ }^{-}$generation and reduced antioxidant defense system disrupts cellular function and Reid et al. (69) found that with aged individuals this imbalance between ROS and antioxidant defense systems could significantly affect muscle force production.

ROS can influence NO bioavailability in two ways. First, it scavenges NO to produce peroxynitrite. Second, it decreases the concentration of a co-factor, tetrahydrobiopterin, which is essential for the production of NO by NOS $(38,39)$. NO and ROS compete for the same binding areas located on proteins, which could reduce the ability of NO to produce vasodilation (68). An increase in ROS production can also occur when a reduced availability of L-arginine is present causing NOS to produce $\mathrm{O}_{2}^{-}$instead of $\mathrm{NO}$ (68). Although ROS (i.e., $\mathrm{H}_{2} \mathrm{O}_{2}$ ) play a role in vasodilation it pales in comparison to the vital importance of NO. The increased ROS production causing a lowered NO 
bioavailability along with a reduced antioxidant defense system could produce significant decrements in skeletal muscle vasodilation via reductions in NO bioavailability.

\section{Partial Pressure of Oxygen $\left(\mathrm{PO}_{2 m v}\right)$}

$\dot{Q}_{m}$ and $\dot{\mathrm{V}}_{2 m}$ are of vital importance because they are the primary factors that determine the partial pressure of oxygen in the muscle microvasculature $\left(\mathrm{PO}_{2 m v}\right)$. In the muscle, $\mathrm{PO}_{2 m v}$ is proportional to the ratio of oxygen delivery $\left(\dot{Q} \mathrm{O}_{2 m}\right)$ and the muscle's metabolic rate $\left(\dot{\mathrm{V}} \mathrm{O}_{2 m}\right)\left(\dot{Q} \mathrm{O}_{2 m} / \dot{\mathrm{V}}_{2 m}\right)$. Increases in $\dot{Q}_{m}$ are imperative to provide an adequate driving pressure for $\mathrm{O}_{2}$ to transfer from the capillary to the myocyte during the rest-to-contraction period $(65,85)$ and after reaching the steady state $(7,8,31)$.

In normal young individuals $\dot{Q}_{m}$ and $\dot{Q} \mathrm{O}_{2 m}$ increase at a faster rate than $\dot{\mathrm{V}} \mathrm{O}_{2 m}$, which produces a slower decrease in $\mathrm{PO}_{2 m v}\left(\dot{Q} \mathrm{O}_{2 m} / \dot{\mathrm{V}} \mathrm{O}_{2 m}\right)$ when compared to aged individuals or individuals with disease (i.e., CHF, diabetes) (9-11). The biphasic increase in $\dot{Q}_{m}$ at the onset of contractions coupled with the monoexponential increase in $\dot{\mathrm{V}}_{2 m}$ produces a brief steady state $(10-20 \mathrm{sec})$ in the $\dot{Q} \mathrm{O}_{2 m} / \mathrm{V} \mathrm{O}_{2 m}$ ratio, which is referred to as the time delay (TD). Following the TD the $\mathrm{PO}_{2 m v}$ begins to fall in a monoexponetial manner. However, if the rate of $\dot{Q} \mathrm{O}_{2 m}$ during the transition phase from rest to the steady state of exercise is slowed, it leads to a more rapid decrease in $\mathrm{PO}_{2 m v}(8,24,31)$. This slowed $\dot{Q} \mathrm{O}_{2 m}$ response has been shown to occur in aged individuals primarily and has been primarily ascribed to a diminished bioavailability of NO. Moreover, this slowed $\dot{Q} \mathrm{O}_{2 m}$ response is believed to produce a temporal mismatch between the $\dot{Q} \mathrm{O}_{2 m} / \mathrm{V}_{2 m}$ ratio during the rest-to-steady state contractions producing an "undershoot" of the $\mathrm{PO}_{2 m v}$ response. Eventually, the slowed $\dot{Q} \mathrm{O}_{2 m}$ found in aged individuals is able to meet to the 
$\dot{\mathrm{V}} \mathrm{O}_{2 m}$ by the working muscle and upon equilibration, the $\mathrm{PO}_{2 m v}$ comes to a continual steady state. However, this altered $\mathrm{PO}_{2 m v}$ profile found in the aged individuals could produce a lower driving pressure across the intravascular muscle interface, during the transition from rest to muscle contractions which could slow $\dot{\mathrm{V}}_{2}$ kinetics, increase $\mathrm{O}_{2}$ deficit (26) and increase mitochondrial ROS production (16).

\section{Antioxidant Supplementation}

A very plausible way to increase an individuals antioxidant defense system would be through antioxidant supplementation. Antioxidants work by scavenging free radicals. Thus, antioxidant supplementation should decrease the amount of circulating ROS and could either partially or fully restore endothelial-mediated vasodilation function of aged individuals $(27,79)$. In this regard, an antioxidant that could mimic superoxide dismutase (SOD) (which reacts readily with $\mathrm{O}_{2}^{-}$) along with an antioxidant that acts like catalase (to produce water and $\mathrm{O}_{2}$ from $\mathrm{H}_{2} \mathrm{O}_{2}$ ) may restore endothelial vasodilation by reducing the amount of circulating ROS and increasing the bioavailability of NO. Two compounds that are able to work in this fashion are tempol and ascorbic acid (vitamin C).

Tempol is a compound that mimics the enzyme SOD. It readily reacts with $\mathrm{O}_{2}^{-}$ producing $\mathrm{H}_{2} \mathrm{O}_{2}$ and is able to mimic all three types of SOD isoforms which are 1) SOD1 (CuZnSOD); 2) SOD2 (MnSOD); 3) SOD3 (ECSOD). Each type of SOD isoform is located in different anatomical compartments. SOD1 is located in the cytoplasm, SOD2 is positioned in the mitochondria and SOD3 is situated in the extracellular space. Therefore, the infusion of tempol should produce antioxidant effects in all 3 of these anatomical locations and because of its ability to bind with $\mathrm{O}_{2}{ }^{-}$it should potentially produce drastic 
increases in the bioavailability of NO. Consistent with this hypothesis, tempol has been shown lower (i.e., normalize) blood pressure after infusion in hypertensive rats (76).

Ascorbic acid is able to scavenge ROS and increase the concentration of NO. Ascorbic acid mimics the enzyme catalase by producing $\mathrm{H}_{2} \mathrm{O}$ and $\mathrm{O}_{2}$ from $\mathrm{H}_{2} \mathrm{O}_{2}$. Ascorbic acid improves endothelial function by also stabilizing tetrahydrobiopterin (37) and alpha-tocopherol (38), which are cofactors for the production of NO. Without the production of these cofactors, the production of NO would be reduced. Thus, ascorbic acid has the potential to increase vasodilation through different mechanisms making it a very appealing for therapeutic use.

Antioxidant supplementation can have negative effects as well as positive effects. If antioxidant supplementation works as described previously then the bioavailability of NO should increase. However, if the bioavailability of NO increases above a certain concentrations it begins to have detrimental effects. In this regard, previous studies have shown that a high bioavailability of $\mathrm{NO}$ will reversibly inhibit mitochondrial respiration by competing with $\mathrm{O}_{2}$ for the same binding site within the electron transport chain (17). In addition, a high bioavailability of NO has been shown to decrease muscle force production (68).

\section{Summary}

Aged individuals demonstrate significant reductions in exercise tolerance and capacity when compared to their younger counterparts. The factors contributing to these reductions in exercise tolerance and capacity appear multifactorial and related to changes in both intra-cellular and extra-cellular function. However, the maintenance of $\mathrm{O}_{2}$

delivery $\left(\dot{Q}_{\mathrm{m}}\right)$ along with the $\mathrm{PO}_{2 m v}$ from the intravascular space to the mitochondria 
appears critical during the transition from rest-to-exercise and these contributions of both conductive and diffusive $\mathrm{O}_{2}$ delivery are significantly reduced in aged individuals.

One of the factors contributing to these decrements in $\mathrm{O}_{2}$ delivery appears to be associated with age-related reductions in NO bioavailability. Moreover, the age-related reductions in NO bioavailability appear to be associated with increases in the generation of ROS along with reductions in antioxidant defense mechanisms found in the muscle of these individuals.

Whether or not antioxidant supplementation would be beneficial in aged individuals remains unclear this time. However, based on previous studies it appears plausible that antioxidant supplementation (whether acute or chronic) would prove to be extremely beneficial. In this regard, antioxidant supplementation could significantly reduce ROS and increase NO bioavailability. The increased NO bioavailability could hypothetically increase both $\dot{Q}_{\mathrm{m}}$ and $\mathrm{PO}_{2 m v}$ during the transition from rest-to-exercise, thereby reversing the age-related deficits found in these individuals. The consequence of maintaining or enhancing $\dot{Q}_{\mathrm{m}}$ and $\mathrm{PO}_{2 m v}$ would be the amelioration of age-related deficits in both conductive and diffusive $\mathrm{O}_{2}$ delivery, the normalization of both $\mathrm{PO}_{2 m v}$ and $\dot{\mathrm{V}} \mathrm{O}_{2 \mathrm{~m}}$ profiles during the transition from rest-to-exercise (muscle contractions), along with potential increases in both exercise tolerance and capacity. The end result being an increase in the quality of life for these individuals. 


\title{
CHAPTER 3 - Methods
}

\begin{abstract}
Animals
Twenty old (26-30 months, body mass $563 \pm 19$ g) male Fisher 344x Brown Norway hybrid rats were used in this investigation and were kept completely sedentary. Rats were maintained on a 12:12-h light: dark cycle and received water and food $a b$ libitum. Upon completion of the experiment, each rat was killed with pentobarbital sodium overdose. All protocols were approved by the Kansas State University Institutional Animal Care and Use Committee (IACUC), conformed with guiding principles of the American Physiological Society and were conducted according to the National Institutes of Health Guidelines.
\end{abstract}

\section{Surgical Preparation}

All rats were anaesthetized with pentobarbital sodium (50 $\mathrm{mg} \mathrm{kg}^{-1}$ i.p., to effect) and placed on a heating pad to maintain a constant body temperature of $37-38^{\circ} \mathrm{C}$. The carotid and tail (caudal) arteries were cannulated (Polyethylene-50, Intra-Medic tubing; Clay Adams, Sparks, MD, USA) for infusion of the phosphorescent probe palladium meso-tetra (4-carboxyphenyl) porphyrin dendrimer (R2; $15 \mathrm{mg} \mathrm{kg}^{-1}$ ), monitoring of arterial blood pressure and heart rate (Digi-Med BPA model 200, Louisville, KY, USA) and blood withdrawal. Catheter placement also permitted the measurement of resting and contracting muscle blood flow $\left(\dot{Q}_{m}\right)$ using the radiolabeled microsphere technique (52, $62)$. 
Skin and fascia around the mid-dorsal region of the rat was reflected back to expose the right spinotrapezius muscle. Stainless steel electrodes were sutured to the rostral (cathode) and caudal (anode) region of the spinotrapezius using 6-0 sutures to ensure that electrode position remained unchanged throughout the experimental protocols.

\section{Measurement of Microvascular $\mathrm{PO}_{2}$}

$\mathrm{PO}_{2 m v}$ measurements were made using a PMOD 1000 Frequency Domain Phosphorimeter (Oxygen Enterprises, Ltd., Philadelphia, PA). After exposure of the right spinotrapezius, the common end of the bifurcated light guide was placed 2-3 $\mathrm{mm}$ above the medial region of the muscle and excitation light focused on a $\sim 2$ mm-diameter circle. The phosphorescence quenching technique for measurement of $\mathrm{PO}_{2 m v}$ is based upon the Stern-Volmer relationship (73), which describes the $\mathrm{O}_{2}$ dependence of phosphorescence decay in the presence of the phosphorescence probe. The phosphorescence signal (700 $\mathrm{nm}$ ) was averaged over $10 \times 200 \mathrm{~ms}$ intervals for all $\mathrm{PO}_{2 m v}$ measurements and these measurements were repeated every $2 \mathrm{~s}$. The phosphorometer utilizes a sinusoidal modulation of the excitation light $(524 \mathrm{~nm})$ at frequencies between $100 \mathrm{~Hz}$ and $20 \mathrm{kHz}$, which allows phosphorescence lifetime measurements from $10 \mu$ s to approximately 2.5 ms.

\section{Measurement of Spinotrapezius Blood Flow}

Spinotrapezius $\dot{Q}_{m}$ was determined using the radionuclide-tagged microsphere technique as described in detail by Musch and Terrell (62). The caudal artery catheter was attached to a Harvard pump (model 907, Cambridge, MA) for blood withdrawal at 
$0.25 \mathrm{ml} \mathrm{min}{ }^{-1}$. Two differentially-labeled $15 \mu \mathrm{m}$ microspheres $\left({ }^{46} \mathrm{Sc},{ }^{85} \mathrm{Sr}\right)(\mathrm{New}$ England Nuclear, Boston MA) were injected through the carotid artery and the catheter flushed with saline. In random order and during steady-state contractions, one isotope was injected under control conditions and the second isotope after antioxidant supplementation. At the end of each experiment, the animal was euthanized and both right and left spinotrapezius muscles along with the right and left kidneys removed. Tissue radioactivity was determined by a gamma scintillation counter (Packard Auto Gamma Spectrometer, Cobra Model 5003) and $\dot{Q}_{m}$ were determined by the reference sample method as described by Ishise et al. (48).

\section{Measurement of $\mathrm{PO}_{2 \mathrm{mv}}$ Dynamics}

The R2 probe was infused via the right carotid artery catheter approximately 15 minutes before the first contraction period. The spinotrapezius was kept moist continuously with Krebs-Henseleit solution. After measuring $\mathrm{PO}_{2 m v}$ in the resting state, the spinotrapezius was stimulated at $1 \mathrm{~Hz}$ for 180 seconds (7-9 volts, $2 \mathrm{~ms}$ pulse duration) using a Grass S88 stimulator (Quincy, MA, USA). During contractions of the right spinotrapezius the non-exposed contralateral (left) spinotrapezius was maintained in a resting (non-contracting) state. Continual measurements of $\mathrm{PO}_{2 m v}$ were made in the right spinotrapezius and recorded every 2 seconds during the 180 -second contraction period. Following the initial contraction period, each animal was given a minimum of 50 minutes for the right spinotrapezius muscle to recover. During this recovery period, animals were infused with either saline or a solution containing the antioxidants (ascorbic acid: 7.6 $\mathrm{mg} / 100 \mathrm{~g}$ and tempol: $300 \mathrm{mmol} / \mathrm{kg}$; dissolved in $1.5 \mathrm{ml}$ saline) and the original contraction protocol was repeated. The dosage of ascorbic acid utilized herein has 
demonstrated beneficial effects in diseased states (i.e., sepsis) by reducing that amount of circulating ROS $(2,83)$. Our concentration of tempol used in the present investigation has exhibited beneficial cardiovascular effects (87).

\section{Measurement of Spinotrapezius Force Production}

In a separate group of aged rats $(n=4)$, the distal end of the right spinotrapezius was ligated and sutured to a stainless-steel wire horseshoe and attached to a nondistensible light weight $(0.4 \mathrm{~g})$ cable linking the muscle to a force transducer. Baseline measurements were made with the spinotrapezius muscle stretched to Lo (length where maximum active tension is reached), which was obtained at $\sim 4 \mathrm{~g}$ passive tension. Muscle force production was measured and recorded continuously at rest and during contractions following the same procedure as those described above for $\dot{Q}_{m}$ and $\mathrm{PO}_{2 m v}$.

\section{Calculations}

\section{Curve fitting}

The dynamics of $\mathrm{PO}_{2 m v}$ were described by means of a non-linear regression analysis using a commercial software package (SIGMAPLOT 7.0I; Systat Software, Point Richmond, CA, USA). Curve fitting of the $\mathrm{PO}_{2 m v}$ results i.e., selection of 1 vs. 2 component models were determined according to three criteria: 1) the coefficient of determination $\left.\left(\mathrm{r}^{2}\right), 2\right)$ the sum of the squared residuals, and 3) visual inspection. The equations used to fit the $\mathrm{PO}_{2 m v}$ kinetics are shown below.

One Component: $\mathrm{PO}_{2 m v}(\mathrm{t})=\mathrm{PO}_{2 m v}(\mathrm{BL})+\Delta \mathrm{PO}_{2 m v}\left(1-\mathrm{e}^{\left.-\left(\mathrm{t}-\mathrm{TD}_{1}\right) / \tau\right)}\right)$

Two Component: $\mathrm{PO}_{2 m v}(\mathrm{t})=\mathrm{PO}_{2 m v}(\mathrm{BL})+\Delta_{1} \mathrm{PO}_{2 m v}\left(1-\mathrm{e}^{\left.-\left(\mathrm{t}-T \mathrm{DD}_{1}\right) / \tau_{1}\right)}\right)+\Delta_{2} \mathrm{PO}_{2 m v}\left(1-\mathrm{e}^{\left.-\left(\mathrm{t}-\mathrm{TD}_{2}\right) / \tau_{2}\right)}\right)$ 
Baseline (BL) corresponds to pre-contraction $\mathrm{PO}_{2 m v}$ and $\Delta_{2} \mathrm{PO}_{2 m v}$ is the amplitude of the $\mathrm{PO}_{2 m v}$ response. Time constants were designated as $\tau_{1}$ and $\tau_{2}$ and $\mathrm{TD}_{1}$ and $\mathrm{TD}_{2}$ and were the independent time delays of the respective responses. When the response profile closely approximated a monoexponential only the primary component was used to fit the data. The two-component model was used whenever an "undershoot" was evident and the criteria listed above mitigated the more complex model.

\section{Oxygen Consumption}

$\dot{\mathrm{V}} \mathrm{O}_{2 m}$ was estimated as previously described $(8,58)$. Arterial $\mathrm{O}_{2}$ content $\left(\mathrm{C}_{\mathrm{a}} \mathrm{O}_{2}\right)$ was measured directly (carotid arterial blood) and effluent venous $\mathrm{O}_{2}$ content $\left(\mathrm{C}_{\mathrm{v}} \mathrm{O}_{2}\right)$ was approximated from the $\mathrm{PO}_{2 m v}$ using the rat dissociation curve (" $\mathrm{n} "=2.6$ (Hill coefficient)), the measured hemoglobin concentration ([Hb]), $\mathrm{P}_{50}$ of $38 \mathrm{mmHg}$ and an $\mathrm{O}_{2}$ carrying capacity of $1.34 \mathrm{ml} \mathrm{O}_{2} \mathrm{~g} \mathrm{Hb}^{-1}$ ) (58). Steady-state measurements of spinotrapezius blood flow made at rest and during muscle contractions were then used to calculate $\dot{\mathrm{V}} \mathrm{O}_{2}$ using the Fick Equation [i.e. $\left.\dot{\mathrm{V}} \mathrm{O}_{2}=\dot{Q} \times\left(\mathrm{C}_{\mathrm{a}} \mathrm{O}_{2}-\mathrm{C}_{\mathrm{v}} \mathrm{O}_{2}\right)\right]$.

\section{Stability and Reproducibility of the Spinotrapezius Preparation}

We have shown previously in our laboratory that the isolated spinotrapezius muscle preparation is physiologically stable and viable following the completion of this surgery (4). In addition, we have shown previously with the spinotrapezius preparation that we can retain reproducible $\mathrm{PO}_{2 m v}$ results during the transition from rest to muscle contractions when a minimum of 20 minutes of recovery is allowed between exercise bouts (B.J. Behnke, P. McDonough, T.I. Musch, D.C. Poole, unpublished findings). We re-affirmed the stability and reproducibility of the spinotrapezius preparation in the 
present investigation by examining the $\mathrm{PO}_{2 m v}$ kinetics in 16 animals using the initial and subsequent contraction paradigm. Results demonstrated that reproducibility from the initial to the second contraction bout was excellent. Specifically, there was no change qualitatively in the $\mathrm{PO}_{2 m v}$ profile nor quantitatively $(\mathrm{P}>0.05)$ in any of the variables or parameters measured.

\section{Statistical Analysis}

The effects of the antioxidant supplementation on $\mathrm{PO}_{2 m v}, \dot{Q}_{m}$ and force production were analyzed by Student t-tests and force production was also analyzed by a repeated ANOVA. Statistical significance was accepted at $\mathrm{P}<0.05$ and data are reported as mean $\pm \mathrm{SEM}$. 


\section{CHAPTER 4 - Results}

\section{Microvascular Partial Pressure of Oxygen $\left(\mathrm{PO}_{2 m v}\right)$}

Similar to previous findings in our laboratory (9), the aged rats demonstrated a biphasic $\mathrm{PO}_{2 m v}$ profile during the transition from rest to steady state contractions that consisted of a significant undershoot followed by a rise in the $\mathrm{PO}_{2 m v}$ to the steady-state level (Figure 4-1). Moreover, these findings were similar to our control rats that received saline instead of antioxidant supplementation. Following the infusion of antioxidants $\mathrm{PO}_{2 m v}$ at rest increased significantly from $30.6 \pm 0.9$ to $35.7 \pm 0.8 \mathrm{mmHg}(\mathrm{P}<0.05$, Figure 4-1, Table 4-1). Moreover, the $\mathrm{PO}_{2 m v}$ profile found following the onset of contractions was changed significantly as the "undershoot" found in the control condition was either greatly reduced or eliminated (Figure 4-1 \& 4-2, Table 4-1). Consequently, after antioxidant supplementation, the $\mathrm{PO}_{2 m v}$ rest-to-contractions profile resembled closely that found previously in young animals (Figure 4-1, Table 4-1; (9)). The infusion of antioxidants also changed the magnitude of the $\mathrm{PO}_{2 m v}$ response as the reduction in $\mathrm{PO}_{2 m v}$ from rest to steady-state contractions increased from $13.8 \pm 1.1$ to $18.8 \pm 1.1 \mathrm{mmHg}$ $\left(\mathrm{P}<0.01\right.$, Table 4-1). This increase in the magnitude of the $\mathrm{PO}_{2 m v}$ response was primarily due to the increase in $\mathrm{PO}_{2 m v}$ found at rest following the infusion of antioxidants (Figure 4-1, Table 4-1) as the $\mathrm{PO}_{2 m v}$ measured during steady-state contractions was not different following supplementation $(19.7 \pm 1.2$ vs. $17.7 \pm 1.0 \mathrm{mmHg}, \mathrm{P}>0.05$, Table $4-1)$. 


\section{Muscle Blood Flow $\left(\dot{Q}_{m}\right)$ and Conductance}

Since $\mathrm{PO}_{2 m v}$ is dependent on the relationship of $\dot{Q} \mathrm{O}_{2 m}$ to $\dot{\mathrm{VO}}{ }_{2 m}$ changes in $\dot{Q}_{m}$ exert a commanding influence on $\mathrm{PO}_{2 m v}$ during the transition from rest to muscle

contractions. $\dot{Q}_{m}$ measured in the resting left spinotrapezius muscle was not significantly altered following antioxidant supplementation (Figure 4-3). In contrast, $\dot{Q}_{m}$ in the contracting right spinotrapezius muscle decreased significantly $(42 \%)$ following the infusion of antioxidants. Antioxidant supplementation affected the resting hindlimb locomotor $\dot{Q}_{m}$ somewhat differently however. Specifically, at rest $\dot{Q}_{m}$ was either increased (i.e., soleus) or tended to increase following antioxidant supplementation (Table 4-2).

Antioxidant supplementation lowered mean arterial pressure (MAP) significantly from $131 \pm 5$ to $107 \pm 4 \mathrm{mmHg}(\mathrm{P}<0.05)$, respectively. When spinotrapezius $\dot{Q}_{m}$ was normalized to MAP and expressed as conductance, antioxidant supplementation had no significant effect on conductance (Table 4-3). In contrast, for the hindlimb locomotor muscles vascular conductance was substantially elevated following the infusion of antioxidants (Table 4-3).

\section{Oxygen Consumption $\left(\dot{\mathrm{V}} \mathrm{O}_{2 m}\right)$}

Since $\mathrm{PO}_{2 m v}$ is dependent on the $\dot{Q} \mathrm{O}_{2 m}$ to $\dot{\mathrm{V}} \mathrm{O}_{2 m}$ relationship, alterations in $\dot{\mathrm{V}} \mathrm{O}_{2 m}$ could also have significant effects on $\mathrm{PO}_{2 m v}$ during the rest-to-contraction transition. 
Antioxidant supplementation had no significant effect on the $\dot{\mathrm{V}} \mathrm{O}_{2 m}$ estimated for the spinotrapezius muscle at rest (Figure 4-5). Although antioxidant supplementation had no significant effect in the arterial $\mathrm{O}_{2}$ content $\left(\mathrm{C}_{\mathrm{a}} \mathrm{O}_{2}\right)$, we found that the infusion of antioxidants produced a significant increase in the venous $\mathrm{O}_{2}$ content $\left(\mathrm{C}_{\mathrm{v}} \mathrm{O}_{2}\right)$ estimated from $\mathrm{PO}_{2 m v}$. This resulted in a significant decrease in the a- $\mathrm{vO}_{2}$ diff following antioxidant supplementation (Table 4-4) but due to inter-animal variability this was not associated with any significant changes in the resting $\dot{\mathrm{VO}}_{2 m}$ (Table 4-4).

Following antioxidant supplementation there was a trend for $\dot{\mathrm{V}} \mathrm{O}_{2 m}$ to be reduced during steady state contractions $(\mathrm{P}=0.13)$. This antioxidant-induced trend towards a decreased $\dot{\mathrm{V}} \mathrm{O}_{2 m}$ was associated with a reduction in $\dot{Q}_{m}$ in the absence of significant alterations in $\mathrm{C}_{\mathrm{a}} \mathrm{O}_{2}, \mathrm{C}_{\mathrm{v}} \mathrm{O}_{2}$, or a- $\mathrm{vO}_{2}$ diff (Table 4-4).

\section{Muscle Force Production:}

Because antioxidant supplementation reduced $\dot{Q}_{m}$ significantly and tended to decrease $\dot{\mathrm{VO}}_{2 m}$ it was important to determine the effects of antioxidant supplementation on muscle force production. Antioxidant supplementation produced a significant decrease in the amount of force that was generated in the contracting right spinotrapezius muscle during a constant voltage stimulus. Force generation was reduced $16.5 \%$ within the first contraction and remained depressed throughout the subsequent four-minute contraction period (Figure 4-6). The ratio of the right contracting spinotrapezius muscle force production to $\dot{\mathrm{V}}_{2 m}$ demonstrated a significant increase $(0.92 \pm 0.03,1.06 \pm 0.6$, respectively, $\mathrm{P}<0.05$ ) after antioxidant supplementation. 
Table 4-1: Partial Pressure of Oxygen

\begin{tabular}{|c|c|c|}
\hline & $\begin{array}{c}\text { Before Antioxidant } \\
\text { Supplementation }\end{array}$ & $\begin{array}{c}\text { After Antioxidant } \\
\text { Supplementation }\end{array}$ \\
\hline $\begin{array}{c}\mathrm{PO}_{2 m v} \text { resting baseline } \\
\text { (mmHg) }\end{array}$ & $30.6 \pm 0.9$ & $35.7 \pm 0.8 * *$ \\
\hline $\begin{array}{c}\mathrm{PO}_{2 m v} \text { nadir - exercise } \\
\text { (mmHg) }\end{array}$ & $16.8 \pm 1.2$ & $16.9 \pm 1.0$ \\
\hline $\begin{array}{c}\mathrm{PO}_{2 m v} \text { exercise steady state } \\
\text { (mmHg) }\end{array}$ & $19.7 \pm 1.2$ & $0.8 \pm 0.4 *$ \\
\hline $\begin{array}{c}\mathrm{PO}_{2 m v} \text { 'undershoot' (steady } \\
\text { state - nadir) (mmHg) }\end{array}$ & $2.8 \pm 0.7$ & $18.8 \pm 1.1 * *$ \\
\hline $\begin{array}{c}\mathrm{PO}_{2 m v} \text { (rest-nadir) amplitude } \\
\text { (mmHg) }\end{array}$ & $13.8 \pm 1.1$ & $8.8 \pm 0.6$ \\
\hline TD (s) & $8.5 \pm 0.6$ & $17.1 \pm 2.1$ \\
\hline tau (s) & $14.3 \pm 2.5$ & \\
\hline
\end{tabular}

Microvascular $\mathrm{PO}_{2}\left(\mathrm{PO}_{2 m v}\right)$ values and model parameters measured at rest and during contractions in the right spinotrapezius muscle. Values are means \pm SEM. $* \mathrm{P}<0.05$ vs. pre-infusion and $* * \mathrm{P}<0.01$ vs. pre-infusion. $\mathrm{TD}=$ the time from the onset of initial onset of contractions to initial in decrease in the $\mathrm{PO}_{2 m v}$ profile, tau $=$ the time it takes for $63 \%$ of the initial component to occur. 
Table 4-2: Blood Flow

\begin{tabular}{|c|c|c|}
\hline & $\begin{array}{l}\text { Before Antioxidant } \\
\text { Supplementation }\end{array}$ & $\begin{array}{l}\text { After Antioxidant } \\
\text { Supplementation }\end{array}$ \\
\hline \multicolumn{3}{|l|}{$\underline{\text { Right Muscles }}$} \\
\hline Soleus & $11 \pm 2$ & $26 \pm 5 * *$ \\
\hline Plantaris & $7 \pm 1$ & $15 \pm 4$ \\
\hline Red Gastrocnemius & $11 \pm 3$ & $20 \pm 5$ \\
\hline $\begin{array}{r}\text { White } \\
\text { Gastrocnemius }\end{array}$ & $9 \pm 2$ & $13 \pm 2$ \\
\hline $\begin{array}{r}\text { Mixed } \\
\text { Gastrocnemius }\end{array}$ & $7 \pm 1$ & $8 \pm 2$ \\
\hline $\begin{array}{r}\text { Extensor Digitorum } \\
\text { Longus }\end{array}$ & $7 \pm 1$ & $12 \pm 4$ \\
\hline \multicolumn{3}{|l|}{$\underline{\text { Left Muscles }}$} \\
\hline Soleus & $9 \pm 2$ & $16 \pm 6$ \\
\hline Plantaris & $8 \pm 1$ & $10 \pm 3$ \\
\hline Red Gastrocnemius & $14 \pm 3$ & $24 \pm 6$ \\
\hline $\begin{array}{r}\text { White } \\
\text { Gastrocnemius }\end{array}$ & $8 \pm 2$ & $12 \pm 2$ \\
\hline $\begin{array}{r}\text { Mixed } \\
\text { Gastrocnemius }\end{array}$ & $6 \pm 1$ & $8 \pm 2$ \\
\hline $\begin{array}{r}\text { Extensor Digitorum } \\
\text { Longus }\end{array}$ & $9 \pm 1$ & $15 \pm 5$ \\
\hline
\end{tabular}

Blood Flow $\left(\dot{Q}_{m}\right)$ measured at rest in various hindlimb locomotor muscles. Values are means $\pm \mathrm{SEM}$ in $\mathrm{ml} \mathrm{min}^{-1} 100 \mathrm{~g}^{-1}$. ** $\mathrm{P}<0.01$ vs. pre-infusion 
Table 4-3: Conductance

\begin{tabular}{|c|c|c|}
\hline & $\begin{array}{c}\text { Before Antioxidant } \\
\text { Supplementation }\end{array}$ & $\begin{array}{l}\text { After Antioxidant } \\
\text { Supplementation }\end{array}$ \\
\hline \multicolumn{3}{|l|}{$\underline{\text { Right Muscles }}$} \\
\hline Soleus & $0.08 \pm 0.01$ & $0.25 \pm 0.05 * *$ \\
\hline Plantaris & $0.06 \pm 0.01$ & $0.14 \pm 0.04 *$ \\
\hline Red Gastrocnemius & $0.09 \pm 0.03$ & $0.20 \pm 0.05 *$ \\
\hline $\begin{array}{r}\text { White } \\
\text { Gastrocnemius }\end{array}$ & $0.07 \pm 0.01$ & $0.12 \pm 0.02 *$ \\
\hline $\begin{array}{r}\text { Mixed } \\
\text { Gastrocnemius }\end{array}$ & $0.06 \pm 0.01$ & $0.07 \pm 0.02$ \\
\hline $\begin{array}{r}\text { Extensor Digitorum } \\
\text { Longus }\end{array}$ & $0.05 \pm 0.01$ & $0.12 \pm 0.04$ \\
\hline Spinotrapezius & $1.22 \pm 0.23$ & $0.76 \pm 0.16$ \\
\hline \multicolumn{3}{|l|}{$\underline{\text { Left Muscles }}$} \\
\hline Soleus & $0.07 \pm 0.01$ & $0.15 \pm 0.05$ \\
\hline Plantaris & $0.06 \pm 0.01$ & $0.10 \pm 0.03$ \\
\hline Red Gastrocnemius & $0.11 \pm 0.02$ & $0.23 \pm 0.06 *$ \\
\hline $\begin{array}{r}\text { White } \\
\text { Gastrocnemius }\end{array}$ & $0.06 \pm 0.02$ & $0.11 \pm 0.03$ \\
\hline $\begin{array}{r}\text { Mixed } \\
\text { Gastrocnemius }\end{array}$ & $0.05 \pm 0.01$ & $0.07 \pm 0.02$ \\
\hline $\begin{array}{r}\text { Extensor Digitorum } \\
\text { Longus }\end{array}$ & $0.07 \pm 0.01$ & $0.15 \pm 0.05$ \\
\hline Spinotrapezius & $0.10 \pm 0.02$ & $0.11 \pm 0.03$ \\
\hline
\end{tabular}

Resting conductance of selected hindlimb locomotor and spinotrapezius muscle when muscle blood flows were normalized to MAP. Values are means \pm SEM in $\mathrm{ml} \mathrm{min}$ ${ }^{1} 100 \mathrm{~g}^{-1} \mathrm{mmHg}^{-1} . * \mathrm{P}<0.05$ vs. pre-infusion and $* * \mathrm{P}<0.01$ vs. pre-infusion 
Table 4-4: Oxygen Consumption

\begin{tabular}{|c|c|c|}
\hline & $\begin{array}{c}\text { Before Antioxidant } \\
\text { Supplementation }\end{array}$ & $\begin{array}{l}\text { After Antioxidant } \\
\text { Supplementation }\end{array}$ \\
\hline \multicolumn{3}{|l|}{$\begin{array}{r}\text { Contracting (Right) } \\
\text { Spinotrapezius }\end{array}$} \\
\hline $\begin{array}{r}\text { Estimated } \mathrm{P}_{\mathrm{v}} \mathrm{O}_{2} \\
(\mathrm{mmHg})\end{array}$ & $19.8 \pm 1.4$ & $18.3 \pm 1.1$ \\
\hline $\mathrm{S}_{\mathrm{v}} \mathrm{O}_{2}$ & $0.16 \pm 0.02$ & $0.13 \pm 0.02$ \\
\hline $\mathrm{C}_{\mathrm{v}} \mathrm{O}_{2}(\mathrm{ml} / \mathrm{dl})$ & $3.0 \pm 0.4$ & $2.5 \pm 0.3$ \\
\hline $\mathrm{a}-\mathrm{vO}_{2} \operatorname{diff}(\mathrm{ml} / \mathrm{dl}) \ddagger$ & $14.5 \pm 0.5$ & $15.0 \pm 0.5$ \\
\hline$\dot{\mathrm{V}} \mathrm{O}_{2}\left(\mathrm{ml} \mathrm{min}^{-1} 100 \mathrm{~g}^{-1}\right)$ & $19.7 \pm 3.2$ & $14.5 \pm 2.9$ \\
\hline \multicolumn{3}{|l|}{$\underline{\text { Resting (Left) Spinotrapezius }}$} \\
\hline $\mathrm{P}_{\mathrm{v}} \mathrm{O}_{2}(\mathrm{mmHg})$ & $30.0 \pm 0.1$ & $36.0 \pm 0.9 * *$ \\
\hline $\mathrm{S}_{\mathrm{v}} \mathrm{O}_{2}$ & $0.35 \pm 0.02$ & $0.463 \pm 0.02 * *$ \\
\hline $\mathrm{C}_{\mathrm{v}} \mathrm{O}_{2}(\mathrm{ml} / \mathrm{dl})$ & $6.3 \pm 0.4$ & $8.4 \pm 0.4 * *$ \\
\hline $\mathrm{a}-\mathrm{vO}_{2} \operatorname{diff}(\mathrm{ml} / \mathrm{dl}) \ddagger$ & $11.2 \pm 0.4$ & $9.1 \pm 0.4 * *$ \\
\hline$\dot{\mathrm{V}} \mathrm{O}_{2}\left(\mathrm{ml} \mathrm{min}^{-1} 100 \mathrm{~g}^{-1}\right)$ & $1.6 \pm 0.4$ & $1.3 \pm 0.3$ \\
\hline
\end{tabular}

Oxygen transport variables calculated for the right contracting spinotrapezius and left resting spinotrapezius muscle. Values are means \pm SEM. $* * \mathrm{P}<0.01$ vs. pre-infusion. $\ddagger$ The mean values for arterial partial pressure of oxygen in the blood $\left(\mathrm{P}_{\mathrm{a}} \mathrm{O}_{2}=88.6 \pm 4.8\right.$ $\mathrm{mmHg})$, arterial oxygen saturation $\left(\mathrm{S}_{\mathrm{a}} \mathrm{O}_{2}=97 \pm 1 \%\right)$, hemoglobin concentration $(\mathrm{Hb}=$

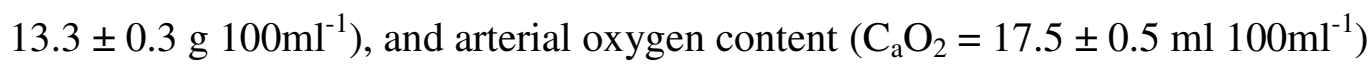
remained unchanged after antioxidant supplementation. 
Figure 4-1: $\mathbf{P O}_{2 m v}$ versus Time

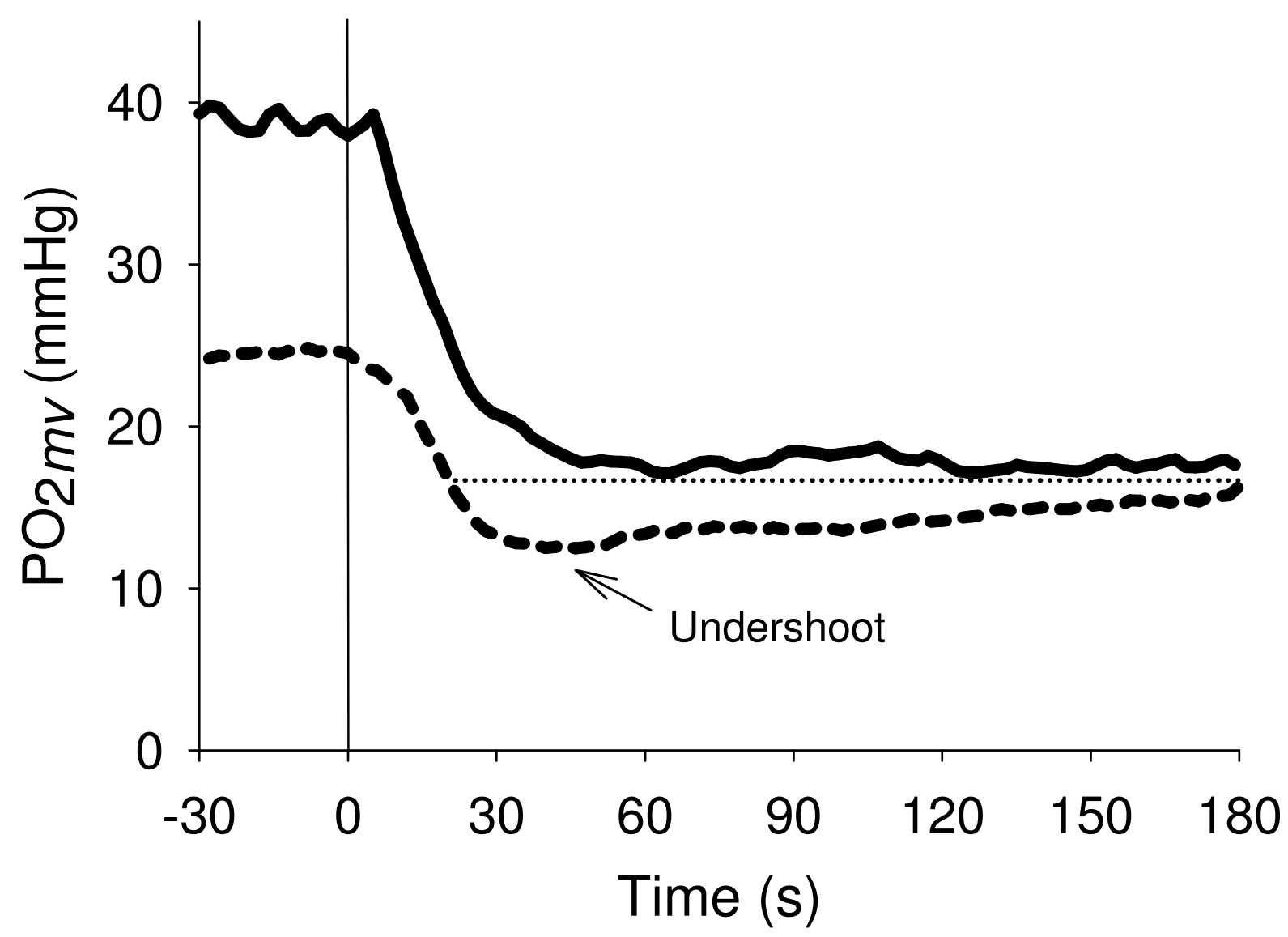

Time course of change in spinotrapezius $\mathrm{O}_{2}$ partial pressure $\left(\mathrm{PO}_{2 m v}\right)$ following the onset of contractions (vertical line at $0 \mathrm{~s}$ ) measured before (dashed line) and after antioxidant supplementation (solid line) for a representative animal. Note the pronounced 'undershoot' of $\mathrm{PO}_{2 m v}$ that drives $\mathrm{PO}_{2 m v}$ below the subsequent end-contraction values. 
Figure 4-2: $\mathbf{P O}_{2 m v}$ 'undershoot'

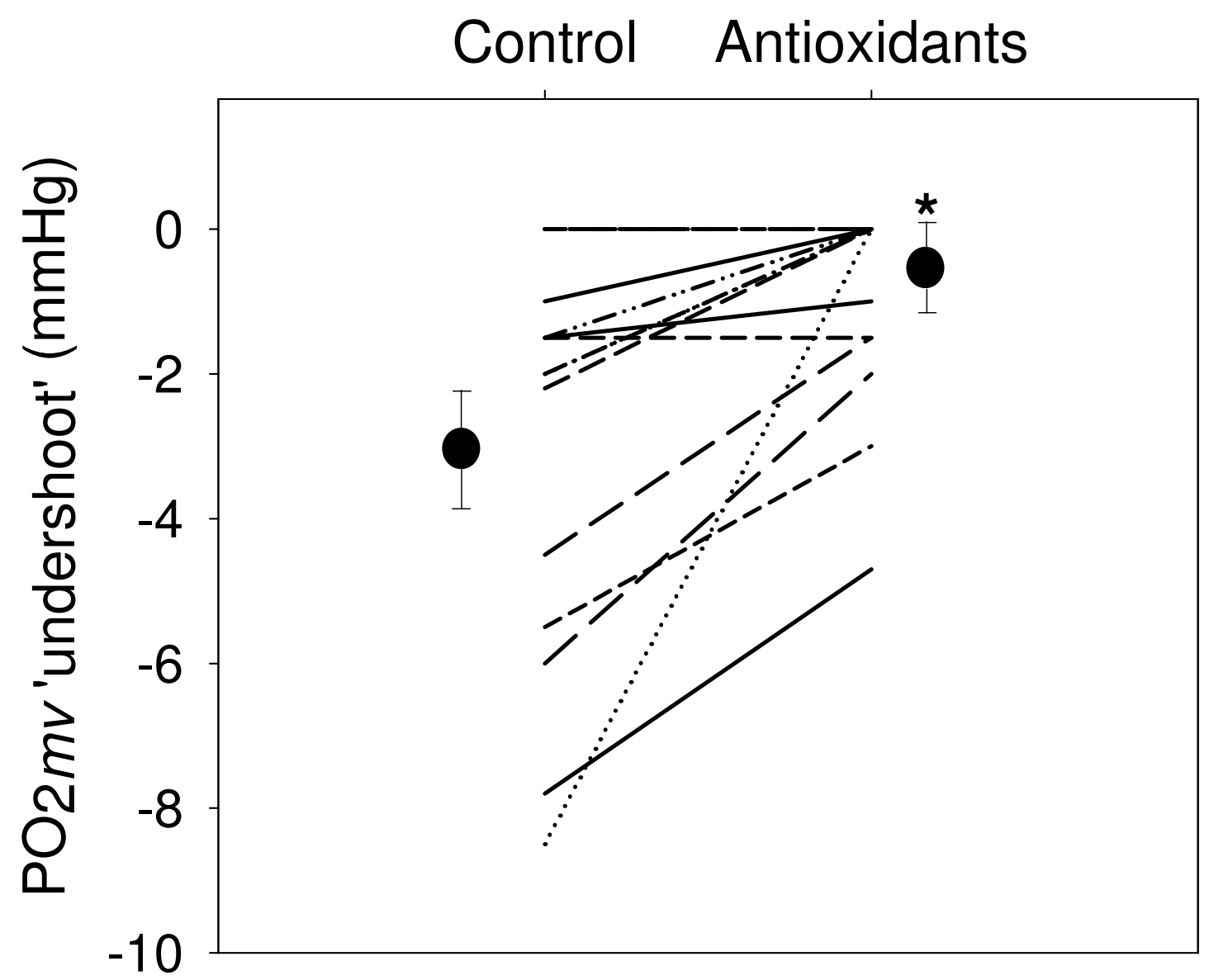

Effect of antioxidant supplementation on the 'undershoot' (see Figure 1 for a visual represenitive of 'undershoot') of microvascular $\mathrm{O}_{2}$ partial pressure $\left(\mathrm{PO}_{2 m v}\right)$ in spinotrapezius muscle $(\mathrm{n}=16)$. Note that in nearly all cases the "undershoot" decreased towards, or became, zero. Animals that illustrated the same response after antioxidant supplementation are illustrated by one line. * Before vs. after supplementation $(\mathrm{P}<$ $0.05)$. 
Figure 4-3: Blood Flow versus Time

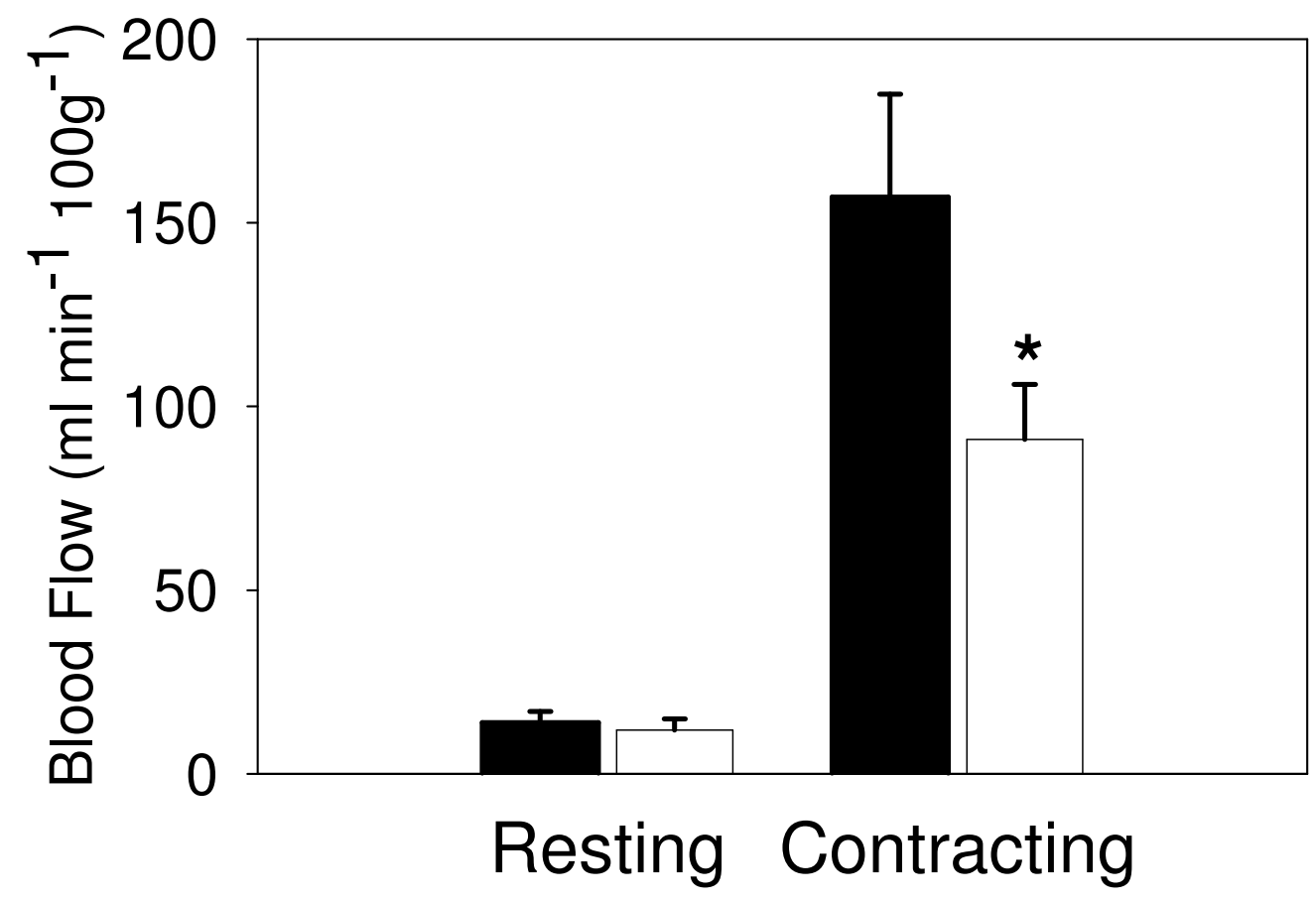

Blood flow $\left(\mathrm{ml} \mathrm{min}^{-1} 100 \mathrm{~g}^{-1}\right)$ to the resting and contracting spinotrapezius muscles measured before (closed box) and after (open box) antioxidant supplementation $(n=7)$. Data are means \pm SEM. * Before vs. after supplementation $(\mathrm{P}<0.05)$. 
Figure 4-4: Conductance versus Time

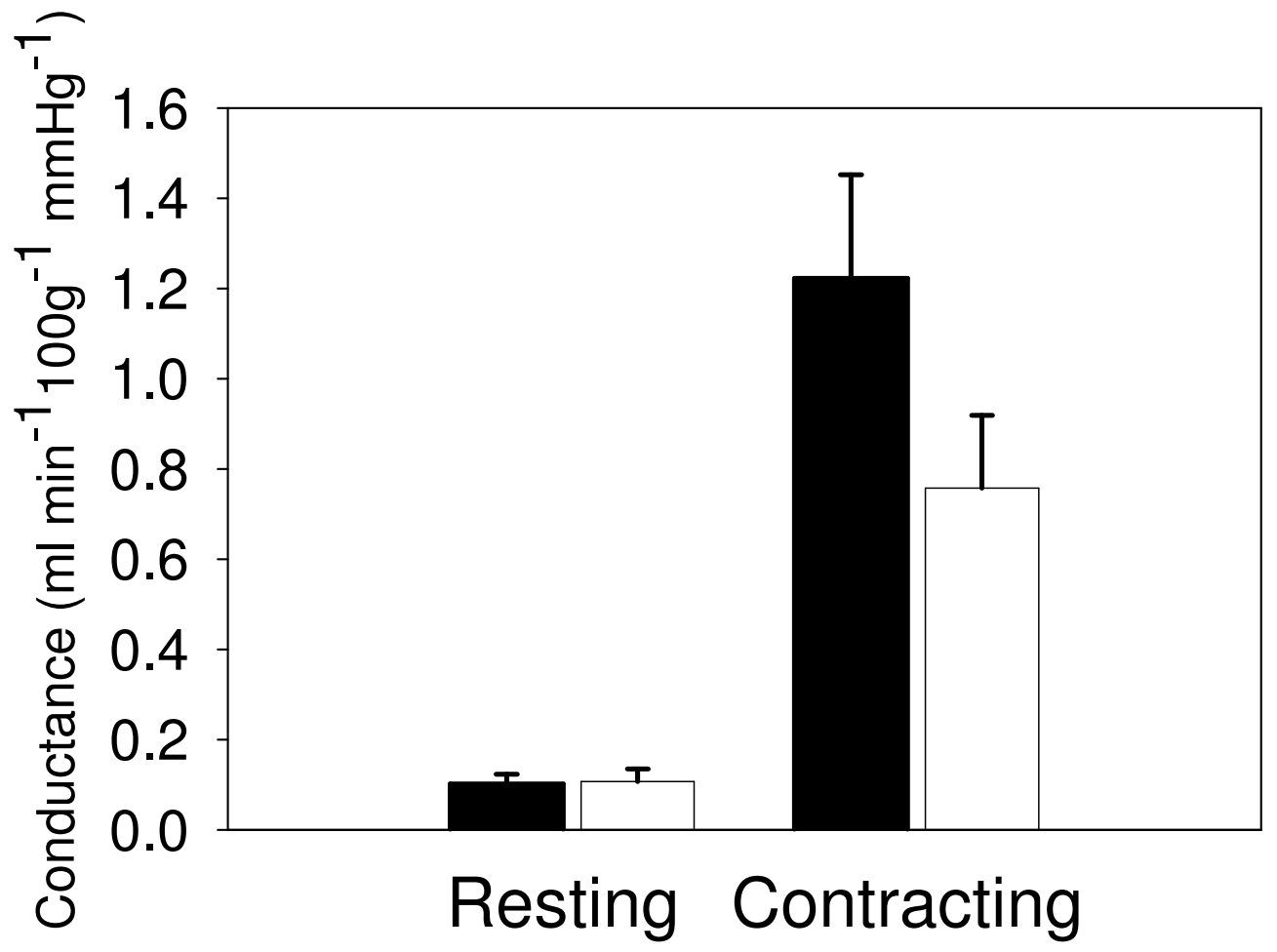

Conductance $\left(\mathrm{ml} \mathrm{min}^{-1} 100 \mathrm{~g}^{-1} \mathrm{mmHg}^{-1}\right)$ to the resting and contracting spinotrapezius muscle before (closed box) and after (open box) antioxidant supplementation $(n=7)$. Data are means \pm SEM. 
Figure 4-5: Oxygen Consumption versus Time

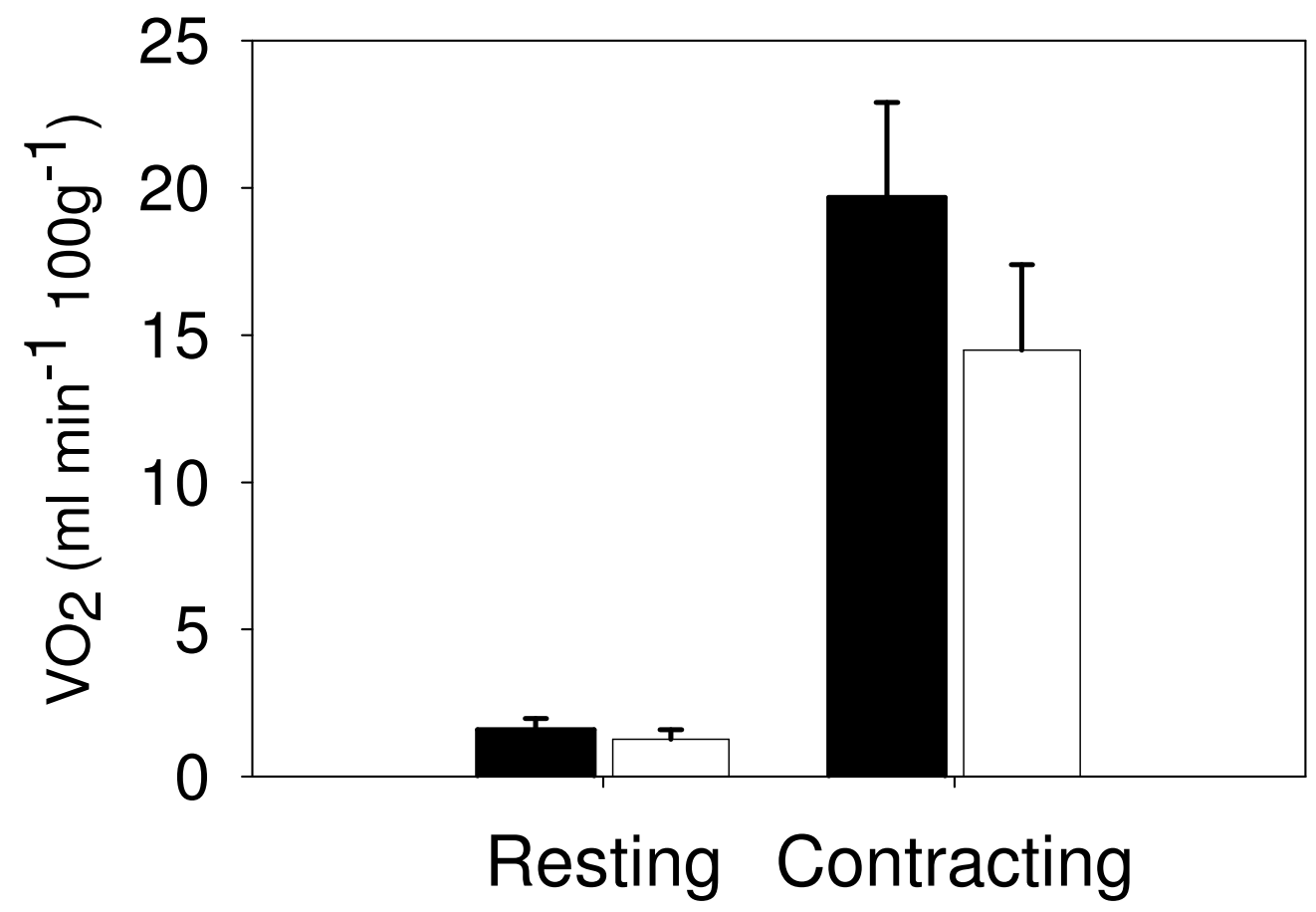

$\dot{\mathrm{V}} \mathrm{O}_{2 m}\left(\mathrm{ml} \mathrm{min}^{-1} 100 \mathrm{~g}^{-1}\right)$ to the resting and contracting spinotrapezius muscles before (closed box) and after (open box) antioxidant supplementation $(\mathrm{n}=6)$. Data are means \pm SEM. 
Figure 4-6: Muscle Force Production versus Time

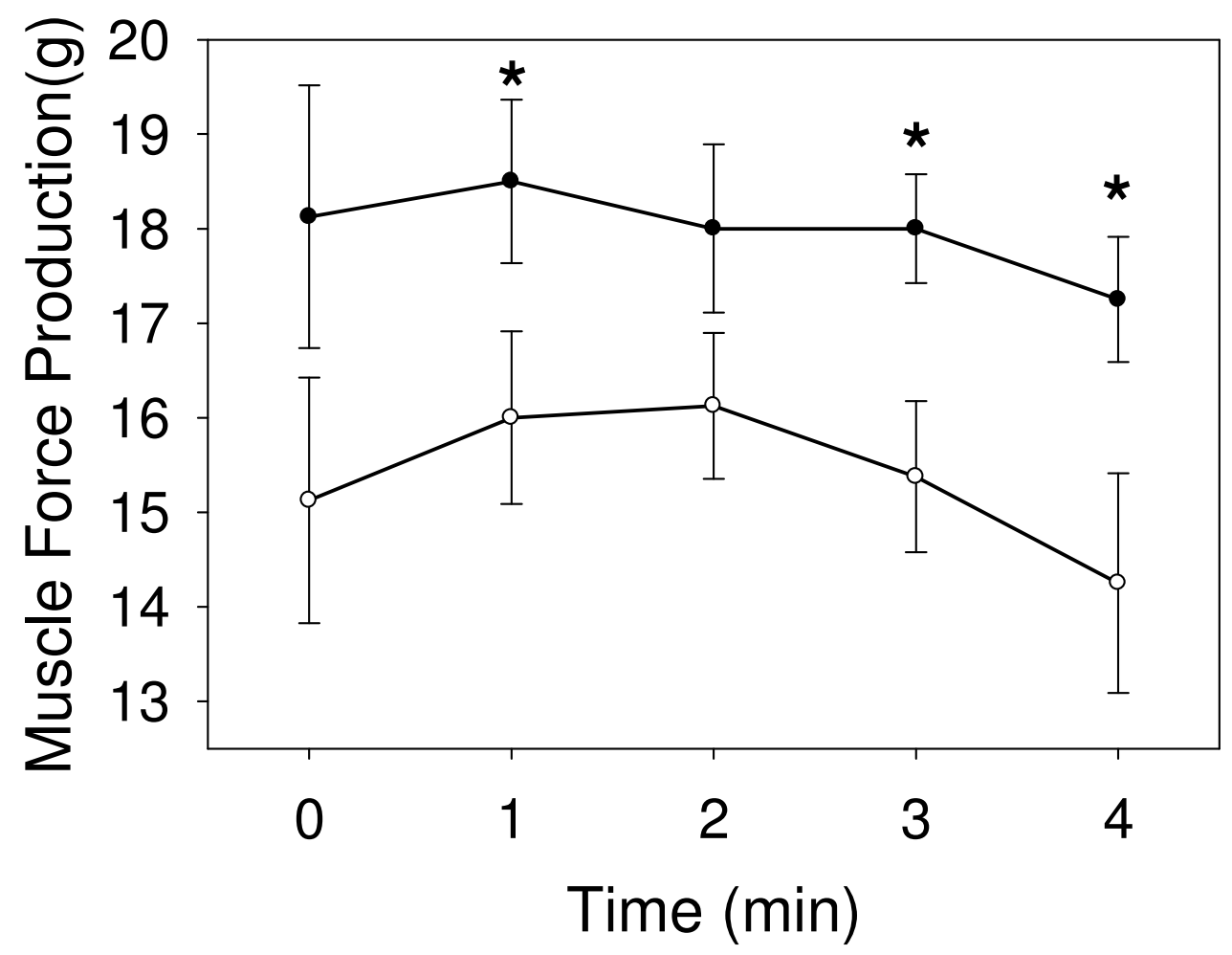

Muscle force production generated by the contracting right spinotrapezius muscle before (closed circles) and after antioxidant supplementation (open circles) $(n=4)$. Data are means \pm SEM. * Before vs. after supplementation $(\mathrm{P}<0.05)$. 


\section{CHAPTER 5 - Discussion}

To our knowledge, the present investigation was the first to examine the effects of antioxidants (tempol and ascorbic acid) on the $\mathrm{PO}_{2 m v}$ kinetics in contracting muscle of aged rats. The principal novel findings of our investigation were that following antioxidant supplementation: 1) the baseline $\mathrm{PO}_{2 m v}$ in the resting spinotrapezius muscle was significantly increased, but $\dot{Q}_{\mathrm{m}}$ remained unchanged; 2) the temporal $\dot{Q} \mathrm{O}_{2 m} / \dot{\mathrm{V}} \mathrm{O}_{2 m}$ mismatch (i.e., $\mathrm{PO}_{2 m v}$ undershoot) found following the onset of contractions during the transition from rest-to-contractions was significantly decreased, but $\dot{Q}_{\mathrm{m}}$ during steadystate contractions was significantly reduced; 3) muscle force production during contraction was significantly impaired; and 4) saline and before infusion of antioxidants demonstrated similar results therefore illustrating the effects witnessed in this study were due to the infusion of antioxidants.

\section{Effects of Antioxidants on $\mathrm{PO}_{2 m v}, \dot{Q}_{m}$ and Conductance at rest}

The resting baseline $\mathrm{PO}_{2 m v}$ found in the spinotrapezius was significantly increased following antioxidant supplementation. This elevation in $\mathrm{PO}_{2 m v}$ was hypothesized to result from elevation of $\dot{Q}_{m}$ and vascular conductance consequent to a decrease in ROS concentration and an increased NO bioavailability. However, $\dot{Q}_{m}$ and spinotrapezius conductance remained either unchanged or even decreased slightly in contrast to select locomotor muscles (Tables 4-2 \& 4-3). Therefore, with respect to the primary muscle of interest, the spinotrapezius, the present results do not support our original hypothesis number two. 
Skeletal muscles vary in their fiber type composition and function. In this regard, the spinotrapezius muscle contains all of the basic fiber types [41\% type I, 7\% type IIa, $35 \%$ type $\mathrm{IIb}$, and $17 \% \mathrm{IId} / \mathrm{x}]$ found in rats (22), while other muscles may only contain two or three of these predominant fiber types. For example, in the rat, the soleus contains primarily type I fibers $\sim 84 \%$, (22), while other locomotor muscles from the hindlimb contain a variety of fiber types ranging widely in their distribution. We found increases in resting $\dot{Q}_{m}$ and conductance in several different hindlimb locomotor muscles following antioxidant supplementation (Table 4-2 \& 4-3) in a manner that did not appear to be fiber-type dependent. In marked contrast, resting $\dot{Q}_{m}$ and conductance remained unchanged or even decreased slightly in the spinotrapezius muscle following the infusion of antioxidants. The mechanisms responsible for these changes or lack of changes in resting $\dot{Q}_{m}$ and conductance found after antioxidant supplementation are unclear at this time. However, sympathetic activation and/or withdrawal have a commanding effect on $\dot{Q}_{m}$ and conductance (42) and the possibility exists that muscle specific changes in sympathetic vascular tone might have resulted from infusion of antioxidants and thus have contributed to the present results.

The present investigation demonstrated clearly that antioxidant supplementation produced an increase in the resting $\mathrm{PO}_{2 m v}$ of the spinotrapezius muscle without any significant changes in resting $\dot{Q}_{m}$ or conductance to the muscle which implies that the resting metabolic rate $\left(\dot{\mathrm{V}}_{2 m}\right)$ must have decreased. Indeed, there was an absolute $\dot{\mathrm{V}}_{2 m}$ fall of $\sim 10 \%$ in the resting spinotrapezius. However, inter-animal variability appears to have been responsible for the statistical inability to detect this difference at the $\mathrm{P}<0.05$ level. 


\section{Effects of Antioxidants on the transition of $\mathrm{PO}_{2 m v}$ from rest to exercise:}

There are three distinct phases during the transition from rest to exercise in the $\mathrm{PO}_{2 m v}$ profile that have been described previously for the spinotrapezius muscle in young rats (11). There is an initial time delay (TD) at the initial onset of contractions where the $\mathrm{PO}_{2 m v}$ profile either remains constant (lasting around $~ 10-20$ seconds) or increases slightly. This has been interpreted as $\dot{Q} \mathrm{O}_{2 m}$ increasing sufficiently to meet the rising $\dot{\mathrm{V}} \mathrm{O}_{2 m}$ demands (11).

In the present investigation the TD before antioxidant supplementation was consistent with that demonstrated previously in aged rats (9). We expected initially that that the antioxidant supplementation would produce an increase in the TD due to an increased bioavailability of NO thereby allowing an increased NO-mediated vasodilation. However, we were surprised to find that the TD was unaffected by antioxidant supplementation (Figure 4-1, Table 4-1) and we attributed this finding to a preservation of the $\dot{Q} \mathrm{O}_{2 m} / \mathrm{V} \mathrm{O}_{2 m}$ ratio albeit at different absolute levels of $\dot{Q} \mathrm{O}_{2 m}$ and $\dot{\mathrm{V}} \mathrm{O}_{2 m}$.

In young, healthy animals after the onset of contractions subsequent to the TD the $\mathrm{PO}_{2 m v}$ profile is described by an exponential decrease in the $\mathrm{PO}_{2 m v}$ (Figure 1). This dynamic phase represents an interval when $\dot{\mathrm{V}}_{2 m}$ is still increasing and doing so out of proportion to $\dot{Q} \mathrm{O}_{2 m}$ until the steady-state is reached $(9,11)$. Our laboratory has demonstrated that disease states such as chronic heart failure (24) and diabetes (10), as well as aged individuals (9) express a biphasic post-TD response that is characterized by an "undershoot" or a temporal mismatch between $\dot{Q} \mathrm{O}_{2 m}$ and $\dot{\mathrm{V}} \mathrm{O}_{2 m}$ that is subsequently rectified, presumably as $\dot{Q} \mathrm{O}_{2 m}$ increases later in the contraction bout (i.e., the $\dot{Q} \mathrm{O}_{2 m}$ response is sluggish). The occurrence of this "undershoot" in aged individuals in the 
present investigation is consistent with those previous findings (Figures 4-1 and 4-2). Before the infusion of antioxidants all of the aged rats (i.e., 16 of 16) demonstrated an "undershoot" in the present investigation, which was qualitatively and quantitatively similar to those found previously $(9,10,24)$. This "inadequate" $\dot{Q} \mathrm{O}_{2 m}$ response may occur consequent to an impaired NO-mediated vasodilation.

Thus, following the $\mathrm{TD}$, the overall $\mathrm{PO}_{2 m v}$ was reduced significantly in aged rats when compared to their younger counterparts (9). These reductions in $\mathrm{PO}_{2 m v}$ represent a decreased $\mathrm{O}_{2}$ driving pressure from the muscle microvascular space to the mitochondria during the transition from rest-to-contractions. Previous studies support the idea that there is less NO bioavailability during muscle contractions (i.e., exercise) when aged individuals are compared to their younger counterparts and it is believed that this decreased NO may be mechanistically related to the diminished $\dot{Q}_{m}$ response found in these individuals $(12,27,28,79,80,84)$. It should be noted that previous studies have not examined the effects of antioxidants on the $\mathrm{PO}_{2 m v}$ profile. We originally anticipated that infusion of antioxidants would increase the bioavailability of NO thereby amplifying the vasodilatory response found in the contracting muscle. Contrary to our expectations, we found that spinotrapezius $\dot{Q}_{m}$ was actually reduced which was not consistent with hypothesis number three.

The $\mathrm{PO}_{2 m v}$ profile reaches a steady-state $>60$ seconds after the onset of contractions and this condition is believed to constitute attainment of steady-state levels of both $\dot{Q} \mathrm{O}_{2 m}$ and $\dot{\mathrm{V}} \mathrm{O}_{2 m}$. Our findings indicate that antioxidant supplementation had no significant effect on the contracting steady-state $\mathrm{PO}_{2 m v}$. However, due to the increased resting $\mathrm{PO}_{2 m v}$ found after antioxidant supplementation and the reduced contracting $\dot{Q}_{m}$ 
there was a significant increase in the amplitude of the $\Delta \mathrm{PO}_{2 m v}$ response (Figure 4-1, Table 4-1).

\section{Other Potential Mediators of the $\mathbf{P O}_{2 m v}$ Profile}

Previous studies support the notion that endothelium-mediated vasodilation is reduced in aged skeletal muscle and that this reduction can be ascribed, in part, to an increase in ROS found in this population $(27,35,80)$. The primary source of increased ROS during exercise is thought to be skeletal muscle mitochondria where ROS are generated between complex I and complex III of the electron transport chain (ETC) during oxidative phosphorylation $(13,49)$. Contrary to our expectations following antioxidant supplementation, we found that $\dot{Q}_{m}$ (and therefore $\dot{Q} \mathrm{O}_{2 m}$ ) was significantly decreased during steady-state contractions. Moreover, we found that the calculated $\dot{\mathrm{V}} \mathrm{O}_{2 m}$ was also reduced, contrary to the anticipated beneficial effects on the ETC. Given these findings the likelihood that increased NO bioavailability may have competitively inhibited the binding of $\mathrm{O}_{2}$ in the ETC must be considered (17). Although the infusion of antioxidants may have reduced ROS in the contracting muscle and thereby increased the bioavailability of $\mathrm{NO}$, in turn this increased [NO] may have compromised mitochondrial

function and hence $\dot{\mathrm{V}} \mathrm{O}_{2 m}$. Since the $\dot{Q}_{m}$ response found in skeletal muscle is tightly coupled to oxidative metabolism (i.e., $\dot{\mathrm{V}}_{2 m}$ ) under exercising (contracting) steady-state conditions (23), the probability exists that any potential increase in vasodilatory function was effectively offset by reductions in oxidative metabolism (Table 4-4, Figure 4-5) with the net effect that both $\dot{Q}_{m}\left(\dot{Q} \mathrm{O}_{2 m}\right)$ and $\dot{\mathrm{V}} \mathrm{O}_{2 m}$ were reduced.

There also may have been direct effects of NO on skeletal muscle contractile 
function which, in addition to decreased $\dot{\mathrm{V}}_{2 m}$, may have impaired muscle force production. Accordingly, previous studies have shown that high concentrations of NO can significantly inhibit muscle force production $(68,69)$. The mechanistic factors associated with this observation are not fully understood at this time, but Reid and colleagues (69) have suggested that muscle-derived ROS and NO can modulate force production via the redox status of the muscle. This relationship has been schematized as a bell-shaped process (Figure 5-1). According to Reid and colleagues (69) in contrast to the young healthy individual whose redox state places them just to the left of the optimal muscle force production on the bell curve their aged counterparts might be placed to the right of optimal muscle force production due to elevated concentrations of ROS which has increased their oxidized state (69). It was our belief that antioxidant supplementation would shift the redox state in aged individuals such their muscle biochemical environment would be closer to that which would normally be found in younger individuals (i.e., closer to optimal/maximal muscle force production). Contrary to our original belief, antioxidant supplementation significantly reduced muscle force production. Due to the effect of antioxidants on ROS it is likely our protocol actually produced a larger-than-anticipated swing towards the reduced state-one consequence of which was reduced muscle force production (Figure 5-1). This effect is likely to be coupled to the lowered $\dot{\mathrm{V}}_{2 m}$ after the infusion of antioxidants. Therefore, the contracting spinotrapezius muscle produced less force at a lower energy $\left(\dot{\mathrm{V}}_{2 m}\right)$ cost. In support of this hypothesis we found that the ratio between force production and $\dot{\mathrm{V}}_{2 m}$ actually increased $\sim 15 \%$ which means that the contracting spinotrapezius muscle was able to increase its force production per unit of $\dot{\mathrm{VO}}_{2 m}$ (i.e., contracting more efficiently) after antioxidant supplementation. This process may have facilitated the improved temporal 
$\dot{Q} \mathrm{O}_{2 m} / \dot{\mathrm{VO}_{2 m}}$ ratio during the transition from rest-to-exercise and is consistent with the elevated transient $\mathrm{PO}_{2 m v}$ profile found in the present investigation.

\section{Model Considerations}

Electrical stimulation produces a fiber recruitment pattern that is dissimilar to that found in vivo and may result in a very different response from that which occurs during voluntary exercise. Notwithstanding this departure form voluntary contractions, the $\mathrm{PO}_{2 m v}$ profile so obtained agrees closely with the profile of muscle effluent venous $\mathrm{PO}_{2}$ seen in studies of humans performing exercise $(6,34)$.

The effects of repeated muscle contractions on muscle fatigue must be considered. Repeated contractions in aged rats may exacerbate the depletion of intramuscular phosphocreatine and glycogen stores. Depletion of these finite energy sources will ultimately contribute to muscle fatigue (86). In the present investigation muscle force production by the contracting spinotrapezius muscle was significantly reduced after antioxidant supplementation. However, throughout each trial the contracting spinotrapezius muscle force production did not fall significantly from minute zero to minute four and independent trials demonstrated that this contraction protocol could be continued $>30$ min without discernable fatigue (K.F. Herspring, S.W. Copp, D.C. Poole and T.I. Musch, unpublished findings). Thus, there are no indications that fatigue secondary to the control bout of contractions could account for the decreased force production seen in the antioxidant trails. 


\section{Limitations}

In this study, young rats were not examined due to the presumption that young rats produce what is considered a "normal" amount of ROS, which is substantially less than that found for aged individuals $(27,35,69,80)$. Thus, when young healthy individuals begin to exercise, muscle force production potential is altered only slightly by increasing ROS production because these individuals shift the force production curve to the right where they reach their optimal contracting state (Figure 5-1). In addition, young rats illustrate a normal $\mathrm{PO}_{2 m v}$ profile $(9,11)$ and the infusion of antioxidants would likely produce detrimental effects on the $\mathrm{PO}_{2 m v}$ profile by generating a greater increase in the NO bioavailability leading to a negative outcome. Thus, we anticipated that antioxidant supplementation in a young healthy rat would not produce the positive findings that we found in the aged rats participating in this study. However, this remains to be demonstrated.

Another potential limitation is that the aged rats (26-30 months) used in the present investigation may not demonstrate the same response as humans with respect to the key variables measured herein and it is also possible that the results of the male rats used in the present investigation may not translate directly to female rats. The spinotrapezius muscle in the rat is used to stabilize the scapula and alterations seen in the spinotrapezius after antioxidant supplementation may not represent other locomotor muscles, note disparate $\dot{Q}_{\mathrm{m}}$ regions herein. However, the spinotrapezius muscle is comprised of a mosaic of muscle fiber types (22) and has oxidative capacity similar to the human quadriceps (54) and in this respect it represents a good comparison to the human locomotor muscle. Finally, it should be noted that we examined only one level of 
submaximal contractions in the present investigation. Therefore, the possibility exists that other exercise intensities or durations may produce significantly different responses than those found in this study.

\section{Future Directions}

Antioxidants have a major modulatory effect on the $\mathrm{PO}_{2 m v}$ found at rest and during the transition from rest-to-exercise. However, the mechanisms associated with the antioxidant-induced $\mathrm{PO}_{2 m v}$ changes remain to be defined precisely. In this study, it can be reasoned that the magnitude of antioxidants administered was so great that it caused a negative effect on the contracting muscle at least with respect to contractile output. Therefore, in future studies it may be important to examine the effects of lower doses of antioxidants on $\mathrm{PO}_{2 m v}, \dot{Q}_{m}$ and muscle function (i.e., force production). Future studies should be designed to help us understand the effects that NO and ROS may play in controlling $\mathrm{PO}_{2 m v}$ at rest and during the transition to exercise.

Examination of the effects of antioxidants on the $\mathrm{PO}_{2 m v}$ in rats with $\mathrm{CHF}$ and diabetes could also provide valuable information. In the present investigation the $\mathrm{PO}_{2 m v}$ profile found for the aged rat before antioxidant supplementation was very similar to those found previously for rats with $\mathrm{CHF}$ and diabetes $(10,24)$. Specifically, we anticipate that the administration of antioxidants would produce similar effects on patients with $\mathrm{CHF}$ and diabetes as those found in our study. Finally, tempol and ascorbic acid were administered together in the present investigation. Administration of each antioxidant individually could be potentially important since both compounds work in different ways and could potentially produce different results when administered separately. 


\section{Conclusion}

Antioxidant supplementation significantly alters the balance between $\dot{Q} \mathrm{O}_{2 m}$ and $\dot{\mathrm{V}}_{2 m}$ at rest and following the onset of muscle contractions which modifies the microvascular $\mathrm{PO}_{2 m v}$ profile. Specifically, antioxidants elevate $\mathrm{PO}_{2 m v}$ at rest which improves the potential for diffusive blood-myocyte $\mathrm{O}_{2}$ flux. This effect arises, in part, from the unanticipated fall in muscle force production consequent to antioxidant supplementation rather than an elevated $\dot{Q} \mathrm{O}_{2 m}$. 
Figure 5-1: Biphasic Muscle Force Production Curve

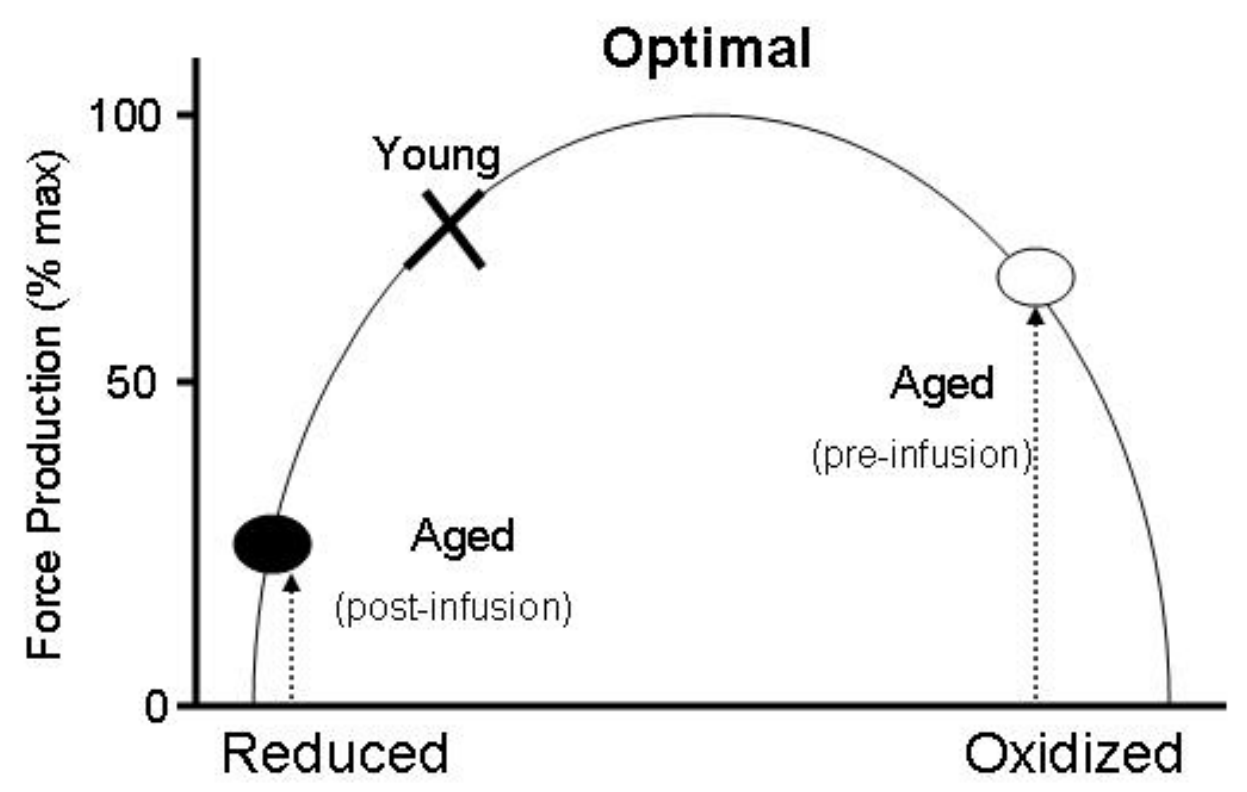

Biphasic response of muscle force production coupled with redox state. Open circle is the muscle force production by aged rats before antioxidant supplementation. Closed circle is the muscle force production by aged rats after antioxidant supplementation. Young healthy rats are indicated by the X. Drawn from the concept described by Reid and Durham (69). 


\section{References}

1. Allbrook DB, Han MF, and Hellmuth AE. Population of muscle satellite cells in relation to age and mitotic activity. Pathology 3: 223-243, 1971.

2. Armour J, Tyml K, Lidington D, and Wilson JX. Ascorbate prevents microvascular dysfunction in the skeletal muscle of the septic rat. J Appl Physiol 90: 795-803, 2001.

3. Babcock MA, Paterson DH, and Cunningham DA. Influence of ageing on aerobic parameters determined from a ramp test. Eur J Appl Physiol Occup Physiol 65: 138-143, 1992.

4. Bailey JK, Kindig CA, Behnke BJ, Musch TI, Schmid-Schoenbein GW, and Poole DC. Spinotrapezius muscle microcirculatory function: effects of surgical exteriorization. American journal of physiology 279: H3131-3137, 2000.

5. Baker PC. The aging neuromuscular system. Semin Neurol 9: 50-59, 1989.

6. Bangsbo J, Krustrup P, Gonzalez-Alonso J, Boushel R, and Saltin B. Muscle oxygen kinetics at onset of intense dynamic exercise in humans. Am J Physiol Regul Integr Comp Physiol 279: R899-906, 2000.

7. Barstow TJ, Lamarra N, and Whipp BJ. Modulation of muscle and pulmonary $\mathrm{O}_{2}$ uptakes by circulatory dynamics during exercise. J Appl Physiol 68: 979-989, 1990.

8. Behnke BJ, Barstow TJ, Kindig CA, McDonough P, Musch TI, and Poole DC. Dynamics of oxygen uptake following exercise onset in rat skeletal muscle. Respir Physiol Neurobiol 133: 229-239, 2002. 
9. Behnke BJ, Delp MD, Dougherty PJ, Musch TI, and Poole DC. Effects of aging on microvascular oxygen pressures in rat skeletal muscle. Respir Physiol Neurobiol 146: 259-268, 2005.

10. Behnke BJ, Kindig CA, McDonough P, Poole DC, and Sexton WL. Dynamics of microvascular oxygen pressure during rest-contraction transition in skeletal muscle of diabetic rats. American journal of physiology 283: H926-932, 2002.

11. Behnke BJ, Kindig CA, Musch TI, Koga S, and Poole DC. Dynamics of microvascular oxygen pressure across the rest-exercise transition in rat skeletal muscle. Respir Physiol 126: 53-63, 2001.

12. Berkowitz DE, White R, Li D, Minhas KM, Cernetich A, Kim S, Burke S, Shoukas AA, Nyhan D, Champion HC, and Hare JM. Arginase reciprocally regulates nitric oxide synthase activity and contributes to endothelial dysfunction in aging blood vessels. Circulation 108: 2000-2006, 2003.

13. Boveris A, Cadenas E, and Stoppani AO. Role of ubiquinone in the mitochondrial generation of hydrogen peroxide. Biochem J 156: 435-444, 1976.

14. Chilibeck PD, Paterson DH, Petrella RJ, and Cunningham DA. The influence of age and cardiorespiratory fitness on kinetics of oxygen uptake. Can J Appl Physiol 21: 185-196, 1996.

15. Chilibeck PD, Paterson DH, Smith WD, and Cunningham DA. Cardiorespiratory kinetics during exercise of different muscle groups and mass in old and young. J Appl Physiol 81: 1388-1394, 1996. 
16. Clanton TL, Zuo L, and Klawitter P. Oxidants and skeletal muscle function: physiologic and pathophysiologic implications. Proc Soc Exp Biol Med 222: 253$262,1999$.

17. Cleeter MW, Cooper JM, Darley-Usmar VM, Moncada S, and Schapira AH. Reversible inhibition of cytochrome c oxidase, the terminal enzyme of the mitochondrial respiratory chain, by nitric oxide. Implications for neurodegenerative diseases. FEBS Lett 345: 50-54, 1994.

18. Coggan AR. Muscle biopsy as a tool in the study of aging. J Gerontol A Biol Sci Med Sci 50 Spec No: 30-34, 1995.

19. Cseko C, Bagi Z, and Koller A. Biphasic effect of hydrogen peroxide on skeletal muscle arteriolar tone via activation of endothelial and smooth muscle signaling pathways. J Appl Physiol 97: 1130-1137, 2004.

\section{Decary S, Mouly V, Hamida CB, Sautet A, Barbet JP, and Butler-Browne} GS. Replicative potential and telomere length in human skeletal muscle: implications for satellite cell-mediated gene therapy. Hum Gene Ther 8: 14291438, 1997.

21. DeLorey DS, Kowalchuk JM, and Paterson DH. Effect of age on $\mathrm{O}_{(2)}$ uptake kinetics and the adaptation of muscle deoxygenation at the onset of moderateintensity cycling exercise. J Appl Physiol 97: 165-172, 2004.

22. Delp MD, and Duan C. Composition and size of type I, IIA, IID/X, and IIB fibers and citrate synthase activity of rat muscle. J Appl Physiol 80: 261-270, 1996. 
23. Delp MD, and O'Leary DS. Integrative control of the skeletal muscle microcirculation in the maintenance of arterial pressure during exercise. $J$ Appl Physiol 97: 1112-1118, 2004.

24. Diederich ER, Behnke BJ, McDonough P, Kindig CA, Barstow TJ, Poole DC, and Musch TI. Dynamics of microvascular oxygen partial pressure in contracting skeletal muscle of rats with chronic heart failure. Cardiovasc Res 56: 479-486, 2002.

25. Donato AJ, Uberoi A, Wray DW, Nishiyama S, Lawrenson L, and Richardson RS. Differential effects of aging on limb blood flow in humans. American journal of physiology 290: H272-278, 2006.

26. Engelen M, Porszasz J, Riley M, Wasserman K, Maehara K, and Barstow TJ. Effects of hypoxic hypoxia on $\mathrm{O}_{2}$ uptake and heart rate kinetics during heavy exercise. J Appl Physiol 81: 2500-2508, 1996.

27. Eskurza I, Monahan KD, Robinson JA, and Seals DR. Effect of acute and chronic ascorbic acid on flow-mediated dilatation with sedentary and physically active human ageing. The Journal of physiology 556: 315-324, 2004.

28. Eskurza I, Myerburgh LA, Kahn ZD, and Seals DR. Tetrahydrobiopterin augments endothelium-dependent dilatation in sedentary but not in habitually exercising older adults. The Journal of physiology 568: 1057-1065, 2005.

29. Ferreira LF, Hageman KS, Hahn SA, Williams J, Padilla DJ, Poole DC, and Musch TI. Muscle microvascular oxygenation in chronic heart failure: role of nitric oxide availability. Acta Physiol (Oxf) 188: 3-13, 2006. 
30. Ferreira LF, Padilla DJ, Williams J, Hageman KS, Musch TI, and Poole DC. Effects of altered nitric oxide availability on rat muscle microvascular oxygenation during contractions. Acta Physiol (Oxf) 186: 223-232, 2006.

31. Ferreira LF, Poole DC, and Barstow TJ. Muscle blood flow- $\mathrm{O}_{2}$ uptake interaction and their relation to on-exercise dynamics of $\mathrm{O}_{2}$ exchange. Respir Physiol Neurobiol 147: 91-103, 2005.

32. Ferrington DA, Jones TE, Qin Z, Miller-Schlyer M, Squier TC, and Bigelow DJ. Decreased conformational stability of the sarcoplasmic reticulum Ca-ATPase in aged skeletal muscle. Biochim Biophys Acta 1330: 233-247, 1997.

33. Gibson MC, and Schultz E. Age-related differences in absolute numbers of skeletal muscle satellite cells. Muscle Nerve 6: 574-580, 1983.

34. Grassi B, Poole DC, Richardson RS, Knight DR, Erickson BK, and Wagner PD. Muscle O2 uptake kinetics in humans: implications for metabolic control. $J$ Appl Physiol 80: 988-998, 1996.

35. Hamilton CA, Brosnan MJ, McIntyre M, Graham D, and Dominiczak AF. Superoxide excess in hypertension and aging: a common cause of endothelial dysfunction. Hypertension 37: 529-534, 2001.

36. Hammer LW, and Boegehold MA. Functional hyperemia is reduced in skeletal muscle of aged rats. Microcirculation 12: 517-526, 2005.

37. Heller R, Unbehaun A, Schellenberg B, Mayer B, Werner-Felmayer G, and Werner ER. L-ascorbic acid potentiates endothelial nitric oxide synthesis via a chemical stabilization of tetrahydrobiopterin. J Biol Chem 276: 40-47, 2001. 
38. Heller R, Werner-Felmayer G, and Werner ER. Alpha-Tocopherol and endothelial nitric oxide synthesis. Ann N Y Acad Sci 1031: 74-85, 2004.

39. Heller R, Werner-Felmayer G, and Werner ER. Antioxidants and endothelial nitric oxide synthesis. Eur J Clin Pharmacol 62 Suppl 1: 21-28, 2006.

40. Hepple RT, Hagen JL, Krause DJ, and Jackson CC. Aerobic power declines with aging in rat skeletal muscles perfused at matched convective $\mathrm{O}_{2}$ delivery. $J$ Appl Physiol 94: 744-751, 2003.

41. Hepple RT, and Vogell JE. Anatomic capillarization is maintained in relative excess of fiber oxidative capacity in some skeletal muscles of late middle-aged rats. J Appl Physiol 96: 2257-2264, 2004.

42. Hijmering ML, Stroes ES, Olijhoek J, Hutten BA, Blankestijn PJ, and Rabelink TJ. Sympathetic activation markedly reduces endothelium-dependent, flow-mediated vasodilation. Journal of the American College of Cardiology 39: 683-688, 2002.

43. Hirai T, Visneski MD, Kearns KJ, Zelis R, and Musch TI. Effects of NO synthase inhibition on the muscular blood flow response to treadmill exercise in rats. J Appl Physiol 77: 1288-1293, 1994.

44. Hirai T, Zelis R, and Musch TI. Effects of nitric oxide synthase inhibition on the muscle blood flow response to exercise in rats with heart failure. Cardiovasc Res 30: 469-476, 1995.

45. Hollenberg M, Yang J, Haight TJ, and Tager IB. Longitudinal changes in aerobic capacity: implications for concepts of aging. J Gerontol A Biol Sci Med Sci 61: 851-858, 2006. 
46. Houmard JA, Weidner ML, Gavigan KE, Tyndall GL, Hickey MS, and Alshami A. Fiber type and citrate synthase activity in the human gastrocnemius and vastus lateralis with aging. J Appl Physiol 85: 1337-1341, 1998.

47. Hunter SK, Thompson MW, Ruell PA, Harmer AR, Thom JM, Gwinn TH, and Adams RD. Human skeletal sarcoplasmic reticulum $\mathrm{Ca}^{2+}$ uptake and muscle function with aging and strength training. J Appl Physiol 86: 1858-1865, 1999.

48. Ishise S, Pegram BL, Yamamoto J, Kitamura Y, and Frohlich ED. Reference sample microsphere method: cardiac output and blood flows in conscious rat. The American journal of physiology 239: H443-H449, 1980.

49. Jezek P, and Hlavata $\mathbf{L}$. Mitochondria in homeostasis of reactive oxygen species in cell, tissues, and organism. Int J Biochem Cell Biol 37: 2478-2503, 2005.

50. Kindig CA, Richardson TE, and Poole DC. Skeletal muscle capillary hemodynamics from rest to contractions: implications for oxygen transfer. $J$ Appl Physiol 92: 2513-2520, 2002.

51. Koga S, Poole DC, Shiojiri T, Kondo N, Fukuba Y, Miura A, and Barstow TJ. Comparison of oxygen uptake kinetics during knee extension and cycle exercise. Am J Physiol Regul Integr Comp Physiol 288: R212-220, 2005.

52. Laughlin MH, Armstrong RB, White J, and Rouk K. A method for using microspheres to measure muscle blood flow in exercising rats. J Appl Physiol 52: 1629-1635, 1982.

53. Lawrenson L, Poole JG, Kim J, Brown C, Patel P, and Richardson RS. Vascular and metabolic response to isolated small muscle mass exercise: effect of age. American journal of physiology 285: H1023-1031, 2003. 
54. Leek BT, Mudaliar SR, Henry R, Mathieu-Costello O, and Richardson RS.

Effect of acute exercise on citrate synthase activity in untrained and trained human skeletal muscle. Am J Physiol Regul Integr Comp Physiol 280: R441R447, 2001.

55. Margreth A, Damiani E, and Bortoloso E. Sarcoplasmic reticulum in aged skeletal muscle. Acta Physiol Scand 167: 331-338, 1999.

56. Mathieu-Costello O, Ju Y, Trejo-Morales M, and Cui L. Greater capillaryfiber interface per fiber mitochondrial volume in skeletal muscles of old rats. $J$ Appl Physiol 99: 281-289, 2005.

57. Mauro A. Satellite cell of skeletal muscle fibers. J Biophys Biochem Cytol 9: 493-495, 1961.

58. McDonough P, Behnke BJ, Padilla DJ, Musch TI, and Poole DC. Control of microvascular oxygen pressures in rat muscles comprised of different fibre types. The Journal of physiology 563: 903-913, 2005.

59. McGuire DK, Levine BD, Williamson JW, Snell PG, Blomqvist CG, Saltin B, and Mitchell JH. A 30-year follow-up of the Dallas Bedrest and Training Study: I. Effect of age on the cardiovascular response to exercise. Circulation 104: 13501357, 2001.

60. Muller-Delp JM, Spier SA, Ramsey MW, and Delp MD. Aging impairs endothelium-dependent vasodilation in rat skeletal muscle arterioles. American journal of physiology 283: H1662-1672, 2002. 
61. Musch TI, Eklund KE, Hageman KS, and Poole DC. Altered regional blood flow responses to submaximal exercise in older rats. J Appl Physiol 96: 81-88, 2004.

62. Musch TI, and Terrell JA. Skeletal muscle blood flow abnormalities in rats with a chronic myocardial infarction: rest and exercise. The American journal of physiology 262: H411-419, 1992.

63. Narayanan N, Jones DL, Xu A, and Yu JC. Effects of aging on sarcoplasmic reticulum function and contraction duration in skeletal muscles of the rat. The American journal of physiology 271: C1032-1040, 1996.

64. Norton MW, Mejia W, and McCarter RJ. Age, fatigue, and excitationcontraction coupling in masseter muscles of rats. J Gerontol A Biol Sci Med Sci 56: B58-65, 2001.

65. Poole DC, Behnke BJ, and Padilla DJ. Dynamics of muscle microcirculatory oxygen exchange. Med Sci Sports Exerc 37: 1559-1566, 2005.

66. Poole JG, Lawrenson L, Kim J, Brown C, and Richardson RS. Vascular and metabolic response to cycle exercise in sedentary humans: effect of age. American journal of physiology 284: H1251-1259, 2003.

67. Proctor DN, Le KU, and Ridout SJ. Age and regional specificity of peak limb vascular conductance in men. J Appl Physiol 98: 193-202, 2005.

68. Reid MB. Role of nitric oxide in skeletal muscle: synthesis, distribution and functional importance. Acta Physiol Scand 162: 401-409, 1998. 
69. Reid MB, and Durham WJ. Generation of reactive oxygen and nitrogen species in contracting skeletal muscle: potential impact on aging. Ann N Y Acad Sci 959: 108-116, 2002.

70. Richardson RS, Poole DC, Knight DR, Kurdak SS, Hogan MC, Grassi B, Johnson EC, Kendrick KF, Erickson BK, and Wagner PD. High muscle blood flow in man: is maximal $\mathrm{O}_{2}$ extraction compromised? J Appl Physiol 75: 19111916, 1993.

71. Rosenheimer JL, and Smith DO. Differential changes in the end-plate architecture of functionally diverse muscles during aging. J Neurophysiol 53: 1567-1581, 1985.

72. Roubenoff R. Origins and clinical relevance of sarcopenia. Can J Appl Physiol 26: 78-89, 2001.

73. Rumsey WL, Vanderkooi JM, and Wilson DF. Imaging of phosphorescence: a novel method for measuring oxygen distribution in perfused tissue. Science 241: 1649-1651, 1988.

74. Russell JA, Kindig CA, Behnke BJ, Poole DC, and Musch TI. Effects of aging on capillary geometry and hemodynamics in rat spinotrapezius muscle. American journal of physiology 285: H251-258, 2003.

75. Scheuermann BW, Bell C, Paterson DH, Barstow TJ, and Kowalchuk JM. Oxygen uptake kinetics for moderate exercise are speeded in older humans by prior heavy exercise. J Appl Physiol 92: 609-616, 2002. 
76. Schnackenberg CG, Welch WJ, and Wilcox CS. Normalization of blood pressure and renal vascular resistance in SHR with a membrane-permeable superoxide dismutase mimetic: role of nitric oxide. Hypertension 32: 59-64, 1998.

77. Schrage WG, Joyner MJ, and Dinenno FA. Local inhibition of nitric oxide and prostaglandins independently reduces forearm exercise hyperaemia in humans. The Journal of physiology 557: 599-611, 2004.

78. Shoemaker JK, and Hughson RL. Adaptation of blood flow during the rest to work transition in humans. Med Sci Sports Exerc 31: 1019-1026, 1999.

79. Taddei S, Virdis A, Ghiadoni L, Salvetti G, Bernini G, Magagna A, and Salvetti A. Age-related reduction of NO availability and oxidative stress in humans. Hypertension 38: 274-279, 2001.

80. Taddei S, Virdis A, Mattei P, Ghiadoni L, Gennari A, Fasolo CB, Sudano I, and Salvetti A. Aging and endothelial function in normotensive subjects and patients with essential hypertension. Circulation 91: 1981-1987, 1995.

81. Trappe S, Gallagher P, Harber M, Carrithers J, Fluckey J, and Trappe T. Single muscle fibre contractile properties in young and old men and women. The Journal of physiology 552: 47-58, 2003.

82. Tschakovsky ME, and Sheriff DD. Immediate exercise hyperemia: contributions of the muscle pump vs. rapid vasodilation. J Appl Physiol 97: 739-747, 2004.

83. Tyml K, Li F, and Wilson JX. Delayed ascorbate bolus protects against maldistribution of microvascular blood flow in septic rat skeletal muscle. Critical care medicine 33: 1823-1828, 2005. 
84. Vanhoutte PM. Ageing and endothelial dysfunction. Eur Heart J Suppl 4 A8A17, 2002.

85. Wagner PD. Determinants of maximal oxygen transport and utilization. Annu Rev Physiol 58: 21-50, 1996.

86. Wilson DF, Erecinska M, Drown C, and Silver IA. The oxygen dependence of cellular energy metabolism. Arch Biochem Biophys 195: 485-493, 1979.

87. Xu H, Fink GD, and Galligan JJ. Tempol lowers blood pressure and sympathetic nerve activity but not vascular $\mathrm{O}_{2}$ - in DOCA-salt rats. Hypertension 43: 329-334, 2004. 